\title{
Architecture of Assimilation \\ A Vernacular approach to housing for China's \\ Rural to Urban Migrants
}

by

Sarah Hormann

A thesis submitted to Faculty of Graduate and Postdoctoral Affairs in partial fulfillment of the requirements for the degree of

degree

in

M. Architecture

Carleton University

Ottawa, Ontario

(C) 2015

Hormann Sarah 

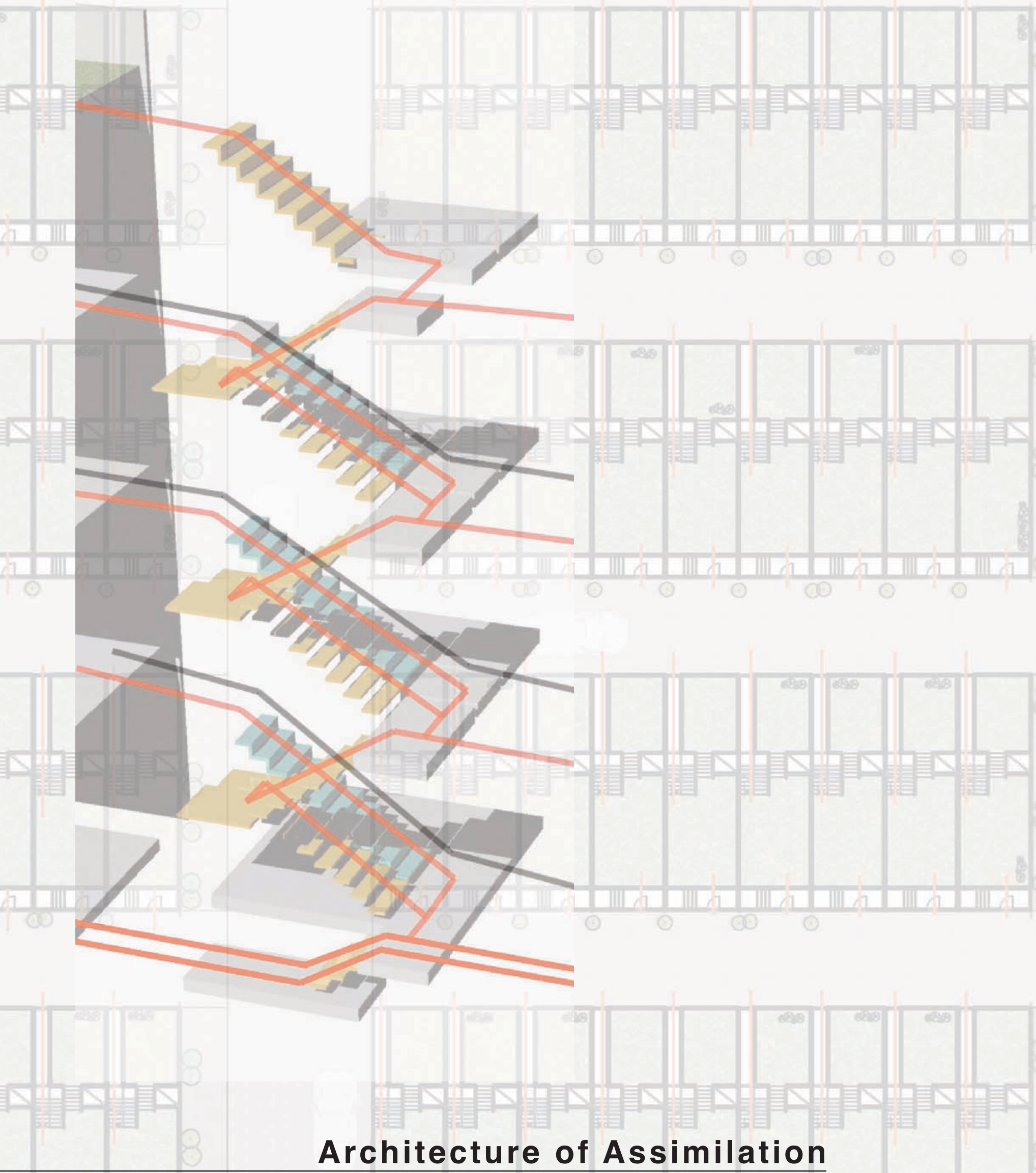

A Vernacular approach to housing for China's Rural-Urban Migrants 


\section{Architecture of Assimilation}

A Vernacular approach to housing for China's Rural to Urban Migrants

By Sarah M. Hormann Advisor: Ben Gianni

2015

A thesis submitted to the Faculty of Graduate and Postdoctoral Affairs in the partial fulfillment of the requirements for the degree of Master of Architecture in M.ARCH (Professional)

Carleton University 1125 Colonel By Drive

Ottawa, On

K1S $5 B 6$ 


\section{Abstract}

China is urbanizing at an unprecedented rate, primarily as a result of rural-tourban migration. Cities have received some 300 million newcomers in the past thirty years, with an additional 400 million Chinese expected to migrate to urban areas by 2050. The promise of prosperity, hope, and the prospect of new identity draw people from the countryside where opportunities are increasingly limited.

Rapid urbanization, however, comes with challenges and consequences, both for migrants and municipalities. New arrivals must forge new identities and adjust to the novel and dynamic environments around them. Established habits must be altered, skills acquired, and social networks expanded. For their part municipal authorities are under immense pressure to produce housing in an efficient and economic fashion. The production of housing, in turn, is an important economic driver and source of employment for unskilled workers.

This thesis considers the experience of rural migrants as they move into urban environments and, specifically, the impact housing form has on their ability to 
assimilate. This issue is particularly acute with respect to unskilled workers, who will likely make up a sizeable proportion of the next wave of migrants. Indeed, Chinese cities are in the process of constructing some 36 million subsidized apartments. ${ }^{1}$

Newcomers of modest means are typically directed to residential high-rises on the periphery of cities. Following the models of Hong Kong and Singapore, large ensembles of towers have become China's default approach to housing over the last several decades. While repetitive towers may be an expedient short-term approach to housing production, high-rise apartments may not be well suited to the needs of the intended inhabitants impeding the process of transition and integration. Questions may be raised regarding the longer-term viability of tower ensembles with respect to the quality and flexibility of the environments they create. While the terms and conditions are by no means identical, postwar "tower-in-the-park" ensembles proved problematic in the west.

In considering alternative approaches to housing, this thesis questions what we might learn from vernacular forms adapted by previous migrants moving into the urban framework. Of particular interest is Shanghai's lilong housing which could be described as a hybrid between the traditional Chinese courtyard house and the western row house. For more than a century, ensembles of lilongs accommodated those migrating to Shanghai to work on the docks and

$1 \quad$ Areddy, James and Davis, Bob, "China Pins Hopes on Public Housing," Wall Street Journal, Dec. 30, 2011. 
in factories. The form was adaptable enough to accommodate the city's middle and upper class residents.

Among the questions to consider, then, is whether, and with what modifications the lilong might present an alternative to China's current predilection for highrise tower ensembles. Accordingly, the design portion of this thesis draws on the lilong to propose a flexible and adaptable housing model to challenge the existing approach to housing form. The goal is to find a culturally resonant approach to housing that better facilitates the formation of social networks, accommodates informal entrepreneurial activity, and eases the transition from rural to urban life. This housing must also be flexible enough to adapt to transformations of urban networks and demographics, over time. 


\section{Table of Contents}

3 Abstract

8 List of Figures

11 Introduction

Relevance

Overview

Intent

Structure

Methodology

21 PART 1: Historical Review

Time line: Migration waves and housing

Housing Types

Housing in the Reform Era

Housing Suitable for Migrants

37 PART 2: China's Approach to the next 400 Million

Introduction

Targets of Migration

Changing the Hukou

Housing Available to Migrants

46 PART 3: Learning from the Lilong

53 Part 4:One Size Fits All Critique

Tower in the park approach

Public Housing

Critique

Informal Arrival City - Liu Gong Li

Peri-Urban Villages

Conclusion 
64 PART 5: Terms of Reference for housing the next "400 Million" Design Problem

Project Background

Content

Market Requirements

Flexibility

Lighting and Ventilation

Open Space

Urban Networks and Scale

The Unit

The Neighborhood

76 PART 6: Unit Design Proposal

One-Bay Unit

Two-Bay Unit

90 PART 7: Conclusion and Reflections

91 Bibliography 


\section{List of Figures}

\section{PART 1: Historical Review}

Figure 1.1 Map of expanding erban development in Shanghai, correlating with time line of political and economic events, and population growth.

Figure 1.2 Courtyard house floor plan

Photo Source (L): Yan Chongnian, Beijing, The Treasures of An Ancient Capital (Beijing: Morning Glory Press: 1987), p. 247.

Figure 1.3 1.4 Photograph of Shikumen stone gate in Shanghai

Figure 1.4 Elevation and section of a Shikumen home

Lu Junhua, Rowe, Peter G., Zhang Jie, Modern Urban Housing in China, 18402000, Munich, London, New York; Prestel Verlag, 2001. pg 66.

Figure 1.5 Lilong neighborhood master plan Lu Junhua, Rowe, Peter G., Zhang Jie, Modern Urban Housing in China, 18402000, Munich, London, New York; Prestel Verlag, 2001. pg 66.

Figure 1.6 An example of a western (axial and symmetrical approach to the layout of a danwei.) "FIGURE 14." URBAN DESIGN International. Web. http://www.palgravejournals.com/udi/journal/v14/n2/fig_tab/udi200912f14.html 31 Mar. 2015.

Figure 1.7 Photograph of Walk-up Apartments in Shanghai

Figure 1.8 Photograph of Tower-in-the-Park developments in Shanghai 
PART 3: Learning from the Lilong

Figure 3.1 Diagram of one-bay lilong

Figure 3.2 Photograph of a washbasin in front of a lilong home in Shanghai's Honkou district.

Figure 3.3 Photograph of an entrance to lilong enclave

Figure 3.4 Diagram of distances between buildings based on building height and sun angles

Figure 3.5 Diagram of growing densities inside a lilong

Figure 3.6 Map of remaining lilong enclaves in Shanghai's Honkou district.

Part 4:One Size Fits All Critique

Figure 4.1 Le Courbusier's Radiant City

Photo Source: http://khorosarchitecture.com/page/3/

Figure 4.2 Rendering of Tower-in-the-Park Development

Photo Source: http://en.51arch.com/2013/05/a511-landscape-design-of-

fuyang-dijingyuan-residential-area/\#PhotoSwipe1423688573327

Figure 4.3 Le Courbusier tower-in-the-Park photo of boulevard

Photo Source: http://envisionbaltimore.blogspot.ca/2013/07/dissolving-

border-vacuums-part-7.html

Figure 4.4 Tower-in-the-Park rendering of entrance gate and towers Photo source: http://en.51arch.com/2013/05/a511-landscape-design-offuyang-dijingyuan-residential-area/

Figure 4.5 Photo of towers in Chongqing http://www.marketplace.org/topics/world/china-fallen-politician-bo-xilai-stillhas-fans

\section{PART 5: Terms of Reference for housing the next "400 Million"}

Figure 5.1 Diagram comparing of lilong structure to a column and slab structure

Figure 5.2 Venn diagram comparing lilong to current market standards

Figure 5.3 Diagram of flexible space inside the lilong

Figure 5.4 Incremental housing by Elemental Chile Photo source: https://favelaissues.files.wordpress.com/2011/12/incrementalhousing2.png

Figure 5.5 Design Concept: Design Concept: pods can be connected in various ways creating flexible unit sizes. 
Figure 5.6 Design Concept: Diagram of lighting and ventilation

Figure 5.7 Photo inside lilong north south alleyway (zong long) in the Honkou district

Figure 5.8 Photograph of new tower in the part developments. View is from Jin Mao Tower showing vast open spaces between buildings

Figure 5.9 Design Concept: Open space created by roof top gardens

Figure 5.10 Map of Shanghai and surrounding urban network (map edited from google maps screen capture)

Figure 5.11 Comparing China's 6-Hectare development size to other city blocks.

Figure 5.12 Lilong network

Figure 5.13 Walk-up apartment network

Figure 5.14 Tower-in-the-Park network

Figure 5.15 Design Concept: Neighborhood networks

Figure 5.16 Design Concept: Interior building networks

Figure 5.17 Design Concept: Neighborhood concept with perimeter commercial buildings

Figure 5.18 Design Concept: Neighborhood concept with perimeter commercial buildings and residential highrises.

Figure 5.19 Design Concept: Block layout and relationships. 


\section{Introduction}

\section{Relevance}

As the balance of China's 1.3 billion citizens make the move from rural life to urban life, it is important to consider the role that housing plays in this transition and in city making, generally. Urban growth is primarily the result of rural-tourban migration, which is in full swing in countries across the globe. ${ }^{1}$ Author Doug Saunders describes the current wave of urbanization as the last great scale of human movement. The approach that China takes to housing for new arrivals will have a long-term impact on the physical and social structure of its cities. Expediency and economies of scale however, largely drive the production of housing in China, as is manifested the predilection for "one-size-fits-all" housing towers. A home is the inhabitant's personal network and thread in the urban fabric. The research of the first chapters in this thesis is important for understanding how the home affects integration of migrants into urban life.

$1 \quad$ Miller, Tom. China's Urban Billion: The Story behind the Biggest Migration in Human History. London: Zed Books ; 2012. pg 8 
Housing can be used as a tool to support the transition from rural to urban life. By taking the needs of migrants into account new housing can contribute to the creation of healthy social networks and help newcomers forge strategic connections to the urban framework. The location of housing within the city, the way units are organized - internally, in relation to other units and with respect to the ground plane - affects the way residents engage with the city and create their own identity. The city is a collective of identities; that collective creates indigenous solutions.

Where migrant housing is concerned, Shanghai's lilong housing was successful in providing a healthy social transition for migrants for over a century. Investigating the advantages and limitations of lilong housing may better prepare us to accommodate the next 400 million migrants. Although the lilong is outdated and departs significantly from housing that the government promotes and the market now produces, there is much to commend it - in particular its cultural specificity, the sense of community it engendered, its adaptability, and the range of activities it supported. By better understanding how architecture and the design of neighborhoods affect the lives of migrants, we can prepare for their arrival.

\section{Overview}

China's top down approach to the provision of housing leaves little room for community participation and even less to chance. Rigid ensembles of highrises are constructed without the input of future residents, often on land that supported aggregations of informal housing. 
Will shifting rural residents into cities address the social divide between rural and urban citizens or merely amplify it? That depends on how quickly migrants can make the transition. This has been a key consideration for low-income populations in other countries including African Americans in the US, Algerians in France, and Turks in Germany.

Where housing for migrants is concerned, we might identify three related issues: overall supply, affordability, and suitability. Arguably China has taken a generic (if efficient) approach to increasing the overall supply, not only to meet but, at least in the short term, to exceed expected demand by way of keeping property prices down. In and among the units currently under construction in China, there are some 36 million "subsidized" units - to be made available for rental, purchase or rent-to-own at below-market rates. ${ }^{2}$ While prior to 1980 virtually all urban housing in China was "rental" housing administered by the state (primarily through state-owned industries), virtually no rental housing has been constructed since reforms were initiated in the late 1970s. Moving citizens to home ownership by giving them title to the units they occupy enables them to benefit from the "unearned increment" as property values rise. Equity in the homes to which they have title, then, is a key component of an equation that lifts people out of poverty (and/or dependence on the State).

2 Areddy, James and Davis, Bob, "China Pins Hopes on Public Housing," Wall Street Journal, Dec. 30, 2011. 
So how would we explain what's been happening in Chinese cities over the past several decades? Giving people title to units they occupied made little sense if this housing was in poor condition or if the space per occupant was drastically below established norms - as was the case with a large proportion of the urban housing stock in China by the end of the 1970s. Legal and logistical issues aside, transferring the title and responsibility for dilapidated, overcrowded and under-serviced property to inhabitants would constitute a burden rather than a benefit.

The land occupied by most urban housing was more valuable than the housing itself. Accordingly, China's strategy has been to shift residents out of the core and into newly built housing on the periphery, where they're given title to larger, better-equipped (and ultimately more market-friendly) units. With residents otherwise accommodated, large tracts of urban housing could be demolished by way of unlocking the value of the land. Lucrative leases on cleared land in the core not only underwrite the cost for replacement housing on the periphery, but fund the infrastructure (schools, roads, transit, police, fire, etc.) necessary to service that housing. As the level of servicing improved, the value of housing on the periphery would further increase.

Ensembles of newly constructed housing on the periphery include both replacement units for displaced residents and additional units for the city's expanding population. Revenues from the sale of 'non-replacement' units (or from the leases on the land on which these units are constructed) are reflected in the cost of the leases. Depending on their economic circumstances, newcomers 
to cities can choose between more expensive housing in the core and moderately priced housing on the periphery. Typically the farther out and less well served by transit, the less expensive the housing.

Here it might be relevant to distinguish between two categories of urban migrants, namely those who come with the resources to procure housing and those who don't. The overall availability and affordability of housing affects both groups. Among those lacking sufficient resources are the so-called floating populations who reside in cities unofficially, i.e., whose household registration status or hukou is elsewhere. With hukou reforms underway in China, unskilled workers will likely comprise an increasing proportion of the next wave of migrants - underscoring the proposition that the demographic profile of the "next 400 million" will be different from the previous cohort.

While there are no doubt many factors at play, China's decision to invest in "subsidized" housing represents an acknowledgement that a significant percentage of the next 400 million will unlikely be able to afford the housing under the terms and conditions in which it's made available through the marketplace. Arguably, however, limiting the discussion of the housing "needs" of this cohort to affordability is myopic. This thesis argues that the discussion of the housing challenges facing migrants of limited means should extend to the (re) consideration of its location and design, not simply the cost at which it's made available. Indeed if need is defined solely in terms of affordability, subsidized housing may be even less favorably located and more generic in its design in order to keep down the cost of its construction. As such the housing 
to which poorer migrants are directed may impede, more than help, the process of integration. Arguably the structure of the built environment matters more to those of limited means as they have fewer resources - financial, social and political - to compensate for its deficiencies or shortcomings.

As with the design of all housing, larger questions of city building are at stake. The design of housing - at the scale of the unit, building and neighborhood largely determines the fabric of cities, which, in turn, affects their resiliency and long-term social and economic sustainability. In his book The Urban Code of China, author Dieter Hassenpflug observes that "In the light of the dramatically increasing degree of urbanization world wide it may not be long before China takes on a leading role in urban design with its type of settlement planning". ${ }^{3}$ China has already directly affected urbanization in Africa as it has started developing cities of mass housing. China's approach to urbanization patterns also indirectly affect the rest of the world as countries learn from each other and create global standards.

China's current approach to housing consists of applying what amounts to a standard template to the build-out of cities. This approach consists of large, repetitive ensembles of high-rise towers. Distinctions between housing for the rich and housing directed to the poor consist less in variations to the basic approach, than in differences in location, quality of finishes, availability of 
amenities, and variations in the size of units. Indeed, the overall consistency in the approach to housing could be considered a good thing inasmuch as the poor are housed as well as the rich. Apartments for all demographic groups enjoy south orientation, and good cross ventilation as interior circulation corridors are kept to a minimum.

For good reason, municipal authorities have been reticent to promote the construction of housing that might be labeled "transitional." Where residents of modest means are concerned, authorities are less interested in (temporarily) warehousing the poor than deploying housing to elevate them - through ownership and the accumulation of equity - into the ranks of the middle class. In this scenario all housing should be designed to suit the middle class because all housing is destined to become middle-class housing. Even the subsidized rental units currently under construction will ultimately find their way into the marketplace as units to be bought and sold.

Unfortunately housing suited to the middle class may not work well for the poor. However different the issues at play (number of children per household, number of single parent households, etc.), this was certainly true of the complexes of high-rise public housing constructed in Europe and North America in the decades following WWII. Towers fared especially poorly when large numbers of poor families were concentrated in the same compound.

The degree to which post-war middle-class housing towers in Europe and Canada were subject to residualization within a decade or two of their construction 
suggests the extent to which the middle-class, too, grew disenchanted with high-rise living. Again, although the circumstances are by no means identical, it's conceivable that the same thing could happen in China, especially when those tower complexes are on the far periphery.

While it might be argued that the population density of China effectively precludes lower-rise alternatives we would do well to remember that The Netherlands whose population density is higher than that of China - has managed to maintain a balance between high- and low-rise housing. Indeed infamous complexes of post-war high-rise housing like Amsterdam's Bijlmermeer complex are being torn down and replaced by row housing.

At issue, then, is whether we can reframe the question. Rather than asking if we can make high-rise residential blocks work for the poor, we should ask whether housing suited to residents of modest means might be able to successfully transition to middle-class housing.

\section{Intent}

In the search for alternatives it should be clarified that it is not my intention to sift through examples of migrant-friendly housing from around the globe in order to identify approaches that China should consider. However relevent and helpful this might be, this is not the focus of the thesis. Rather, the goal is to determine if - and ultimately demonstrate that - indigenous approaches to housing such as the lilong can be brought to bear on building more flexible, resilient and culturally resonant communities in China. 


\section{Structure}

The thesis consists of both written and visual work - design being an essential form of exploration in the field of architecture. Part 1 of the document outlines historical approaches to housing in China while Parts 2 and 4 raise issues with current approaches - particularly in relation to rural-to-urban migrants. Focusing on the Shanghai lilong, Part 3 considers alternatives to high-rise housing, questioning residents' use of space and the affinities between spatial and and social networks. This is supported by the design work in Part 5, which explores ways in which the traditional shikumen house might be modified both to suit the needs of migrants and better operate within the current housing marketplace. Among the many issues at play is whether a case can be made for a provisional return to low-rise housing and, if so, what form it might take at the scale of the unit and that of the neighborhood.

\section{Methodology}

Various methods were employed to investigate the topic of housing for ruralto-urban migrants in China. Books, journals and newspaper articles were consulted to understand the historical, social and economic context for housing in Reform-era China. I also undertook a more limited review of literature to understand how cities elsewhere have responded to the rapid influx of rural-tourban migrants, the implications of various approaches to the build-out of the periphery, and the degree to which unit and neighborhood design affects the ability of migrants to adapt to urban life. 
Reviews of literature were supported by a trip to China with visits to hutong neighborhoods in Beijing and lilong neighbourhoods in Shanghai. Although direct interaction with suburban tower neighborhoods was limited, I was able to observe a number of satellite cities under construction on the trip between Beijing and Shanghai. More first-hand observation would have certainly been helpful, as would detailed investigation of a particular case study. Unfortunately this was beyond the scope of the project at hand.

As noted above, design also formed a critical component of the research. I undertook a series of design studies to assess the extent to which "vernacular" approaches might represent a viable alternative to China's current approach to housing. The focus of these studies was on the ways in which shikumen houses and lilong ensembles might be adapted to be more migrant- and marketfriendly. With additional time and resources, similar studies would have been undertaken at the scale of the neighborhood. 


\section{Historical Review}

The chapter provides background on historical approaches to urban housing in China. Rates of rural-to-urban migration have fluctuated over time reflecting changing economic opportunities and shifts in government policies. Approaches to urban housing, too, have varied over time, reflecting where it is built, who produces it, and the level of demand. Demand, in turn, is largely driven by migration.

The following chart maps rural-to-urban migration in China against housing types, locations, and time periods. While intentionally schematic, the housing types listed are described in greater detail below along with additional historical details. 


\begin{tabular}{|c|c|}
\hline Migration Type & Housing Type \\
\hline $\begin{array}{l}\text { 1. Migration related with growth of economic } \\
\text { activity in Treaty Port cities. } \\
\text { Timeline: 1840s through 1930s. } \\
\text { Description: Some eighty Treaty Ports were } \\
\text { established in China over the course of the } \\
\text { 2nd half of the 19th century. The largest of } \\
\text { these, Shanghai, grew from a population of } \\
\text { about 300,000 in } 1840 \text { to about } 1 \text { million by } \\
\text { 1880. While growth was largely due to the } \\
\text { expansion of trade and industry, Shanghai } \\
\text { also received a large influx of refugees as a } \\
\text { result of the Taiping Rebellion. By } 1936 \text { the } \\
\text { city had reached a population of between } 3 \\
\text { and } 4 \text { million - making Shanghai the world's } \\
\text { 4th largest city behind New York, London } \\
\text { and Paris. }\end{array}$ & $\begin{array}{l}\text { Laneway housing } \\
\text { characterized by the lilong or } \\
\text { longtang of Shanghai. }\end{array}$ \\
\hline $\begin{array}{l}\text { 2. Redistributions of population due to war } \\
\text { and natural disasters. } \\
\text { Timeline: ongoing }\end{array}$ & $\begin{array}{l}\text { Characterized by informal } \\
\text { building and by the doubling } \\
\text { or tripling up of households. }\end{array}$ \\
\hline $\begin{array}{l}\text { 3. Migration related to push for } \\
\text { industrialization during the First and Second } \\
\text { Five Year Plans. } \\
\text { Time line: } 1953-62 \\
\text { Description: China's urban population } \\
\text { doubled (from } 16 \text { to about } 32 \text { million) } \\
\text { between } 1957 \text { and } 1960 \text {. This was followed } \\
\text { by a period of de-urbanization (ruralization) } \\
\text { during the } 1960 \text { s. }\end{array}$ & Danwei housing. \\
\hline $\begin{array}{l}\text { Rural to urban migration associated with the } \\
\text { economic reforms inaugurated in the late } \\
\text { 1970s. } \\
\text { Timeline: } 1979 \text { - present } \\
\text { Description: } \\
\text { Can be divided into three categories: } \\
\text { Those who by reason of skills, influence, } \\
\text { marriage or educational profile were able to } \\
\text { officially relocate to cities by changing their } \\
\text { household registration status. } \\
\text { Those who, due to the expansion of the } \\
\text { geographic and political boundaries of cities, } \\
\text { were reclassified from rural to urban within a } \\
\text { given metropolitan area. } \\
\text { The so-called "floating populations." These } \\
\text { are primarily unskilled workers who, at least } \\
\text { in principle, reside in cities on a temporary } \\
\text { basis and whose hukou status is else where. }\end{array}$ & $\begin{array}{l}\text { 1980s/'90s: six-story walk- } \\
\text { ups. Primarily to replace } \\
\text { substandard (informally } \\
\text { built) housing and to } \\
\text { increase supply by way } \\
\text { of decreasing residential } \\
\text { densities in developed areas. } \\
\mathbf{2 0 0 0 ~ - ~ p r e s e n t : ~ h i g h ~ r i s e ~} \\
\text { slabs - reflective of, among } \\
\text { other things, privatization of } \\
\text { the housing marketplace. } \\
\text { Those residing in cities } \\
\text { without formal registration } \\
\text { status (including the so- } \\
\text { called floating populations) } \\
\text { are housed either in } \\
\text { employer-provided } \\
\text { temporary housing or in } \\
\text { informally built, multi-unit } \\
\text { dwellings on the periphery. }\end{array}$ \\
\hline
\end{tabular}


Figure 1.1 Map of Shanghai, colors represent corresponding time line of population increase.

Expanding Urban Area of Shanghai
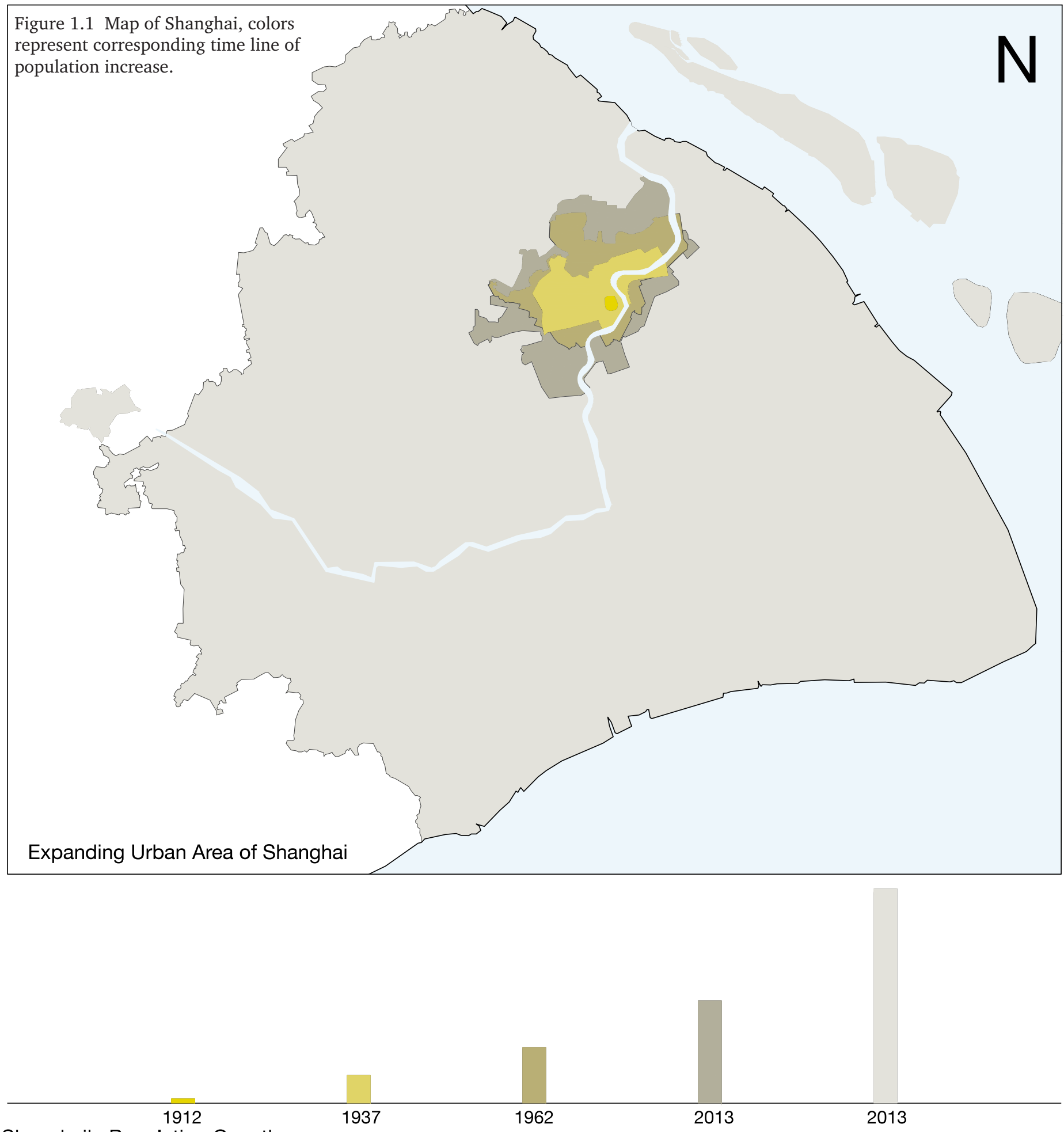

Shanghai's Population Growth

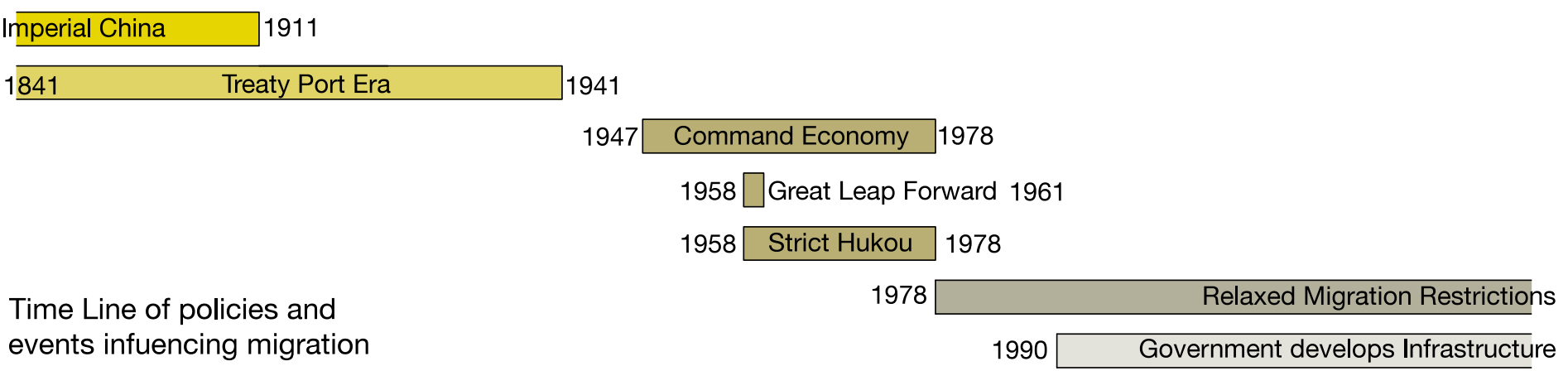




\section{Housing types}

The following section provides brief descriptions of key Chinese housing types, including those identified on the chart above. With the notable exception of housing in the foreign concessions of China's Treaty Ports, approaches to housing in China remained relatively consistent throughout time. While housing in northern China was largely characterized by single-story courtyard houses, cities in the more populous southern portions of China included clustered, multi-story dwellings with smaller courtyards. ${ }^{1}$

\section{Siheyuan or courtyard houses}

The siheyuan, comprised of four, single-story buildings around a courtyard, was the default housing type in northern China. In cities these courtyard houses were frequently aggregated into long, east-west blocks, separated by small alleyways or hutongs. Large parcels of this hutong fabric - largely impenetrable to non-residents - were divided by wider, commercial streets.

\section{Shikumen housing}

house. Each room would have had a specific purpous, however in the hutongs each Under pressure to grow and under the jurisdiction of foreigners, treaty ports room would be a seperage family like Shanghai developed an alternative form of housing. Tight networks of laneways, referred to as lilongs (rather than hutongs), were built out with multistory shikumen or "stone gate" houses.

1 Lu Junhua, Rowe, Peter G., Zhang Jie, Modern Urban Housing in China, 1840-2000, Munich, London, New York; Prestel Verlag, 2001, pg. 41. 
What might be characterized as a cross between the western row house and the Chinese siheyuan, the shikumen was a more efficient and less land-intensive approach to urban housing. Attached houses were built in one-, two- and threebay variations, with bays measuring approximately four meters wide by twelve meters deep. Varying in height from two to four stories, shikumen houses were entered through compact, four-meter (1 bay) wide by three-meter deep courtyards, separated from the laneway by one-story garden walls. Being at the front rather than in the center of the house, the courtyard functioned a bit like a front porch. The moniker "stone gate" refers to the elaborate stone surrounds decorating the doorways to these courtyards.

Shikumen houses were normally divided into two sections: a larger, front portion and smaller, rear lobe, separated by a small light well/stairwell. As ceiling heights in the front of the house were higher than those in the back, the front portions of the shikumen were divided into three stories while the backs incorporated four. The south-facing front portion contained the main rooms of

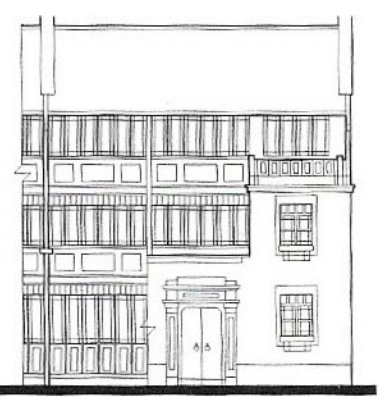
the house while the rear lobe included mostly smaller, service rooms.

Like the hutong neighborhoods in Beijing, shikumen houses were organized into east-west rows, separated by narrow laneways or longs. Because all houses faced south, the fronts of houses in each row faced the backs of those in the adjacent row. Aggregations of lilong housing were frequently organized into

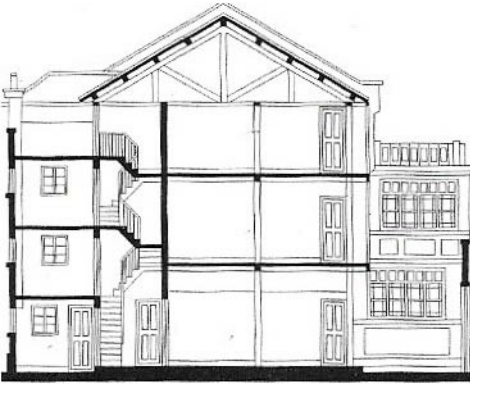

Figure 1.4 Elevation and Section large urban blocks. Depending on the size of the block, aggregations could include up to 200 houses. And depending on the width of the laneways and the size of houses (a function of the number of bays, stories and the overall depth 
of the house), the aggregate densities of these ensembles ranged from about 30 to 80 units per acre (75 to 200 units per hectare). ${ }^{2}$ Actual residential densities varied with the number of households occupying each house which, in turn, depended on the size of the household, the economic profile of the residents, and the overall supply of housing in relation to demand. While originally built to accommodate individual households, even single-bay shikumen houses were designed for multiple households after 1900, typically one family per floor. ${ }^{3}$

Blocks of lilong housing -- defined as repetitive rows of shikumen houses separated by networks of laneways - were frequently enframed by a continuous, two- or three-story 'perimeter block' building. Accommodating commercial usages at street level and a mix of uses above, this circumferential building separated the housing from the wider, public streets surrounding the block. Housing in the interior of the block was accessible though gated archways in the perimeter. Walled off from the city and largely hidden from view, dense lilongs in the center of urban blocks largely functioned like as separate neighborhoods - or even villages - within the city. Notably blocks in Chinese cities are significantly Figure 1.5 Lilong neighborhood larger than those in many Western cities.

As suggested above, among the many interesting features of both hutong and lilong neighborhoods, are the layers of transitions separating the public space of the city from the private space of the house. Transitions are orchestrated

2 Lu Junhua, Rowe, Peter G., Zhang Jie, Modern Urban Housing in China, 1840-2000, Munich, London, New York; Prestel Verlag, 2001. See diagrams of lilong (linong) ensembles on pages $65,66,70$ and 79 .

$3 \quad$ Ibid, pg. 78. 
significantly differently from the way they are in western cities where, in many cases, houses face directly on to public streets. In a typical (if idealized) lilong block, individual houses are entered through courtyards, the gates to which can be closed off and secured. Courtyards, in turn, are entered through east-west laneways (or zhi longs), which are accessed (and can be gated off) from a wider, north-south laneway (or zong long) that bisects the block (see Fig.15). Access to this main laneway is through gated entrances in the perimeter block building. As no houses front onto it, the zong long is able to support a different category of activities than those supported by the smaller east-west passageways.

\section{Danwei Housing}

When the Communist Party took power in 1949, China faced severe, accumulated housing shortages. Not only had little housing been constructed in the 1940s but large amounts of housing had been destroyed as a result of conflicts with the Japanese. The transition to a socialist economy included the expropriation of private property and the reallocation of housing by the State, with multiple households frequently being assigned to the same dwelling. In the 1950s the government took on the construction of housing as part of a larger reorganization of China's economy into a planned economy. Cities were divided into what were referred to as work units or danwei (each associated with a factory or other enterprise) and agricultural land was divided among collectives. Danwei housing typically took the form of 5- and 6-story walk-up apartment blocks arranged in repetitive, south-facing rows. While other arrangements were tried, including 'western style' axial organizations and perimeter block configurations (see Fig. 1.6), "for those considerable number of east-west houses in this type of

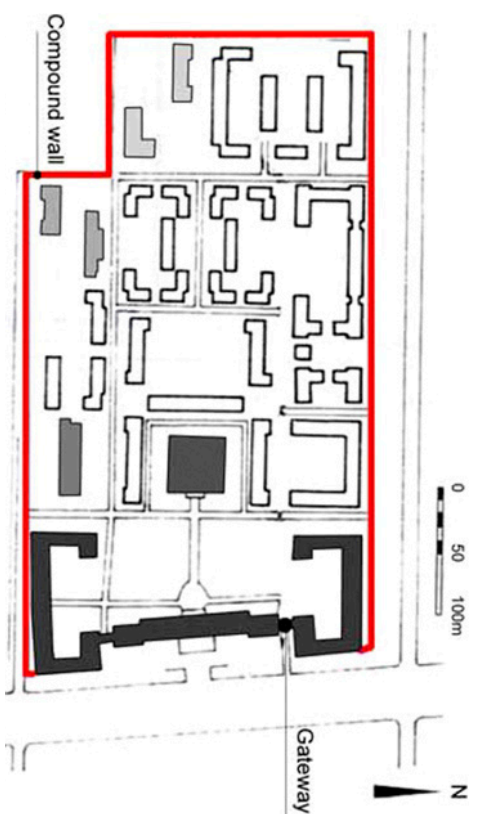

Figure 1.6 An example of a western (axial and symmetrical approach to the layout of a danwei.)

27 
residential area, access to sunlight and ventilation was far from satisfactory, and noise from the street was often disturbing. In addition, the resulting orderly and stern ambience of the neighborhood was not ideal for many residents." ${ }^{4}$

Despite government investment in housing in the early Communist era the amount of space per resident in China remained severely limited. Already the terms of reference for the First Five Year Plan (1953-57) called for a reduction of investment in "non-productive" buildings, resulting in cuts in the allowable cost per sq. ft. for housing and in the percentage reserved for housing within the funds allocated by the state to individual enterprises for capital construction. ${ }^{5}$ "Effectively, ideology made thriftiness a principle that prevailed over everything else; it also became a principle employed to popularize low-standard housing

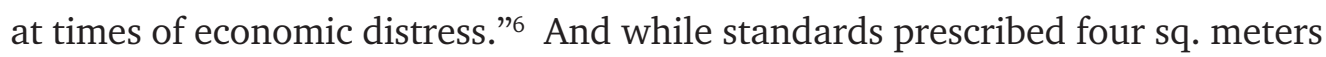
per person in the design of 3- and 4-room apartments, multiple families were often assigned to the same unit. ${ }^{7}$ Following Soviet models, apartment blocks in this era frequently included interior corridors, which proved problematic where cross ventilation and access to sunlight were concerned. ${ }^{8}$

Swelled by some thirty million by the end of the Great Leap Forward (1958-61), urban populations - along with State investment in cities -- dropped off in the 1960s. With the onset of the Cultural Revolution "urban construction entered a

\footnotetext{
4 Lu Junhua, Rowe, Peter G., Zhang Jie, Modern Urban Housing in China, 1840-2000, Munich, London, New York; Prestel Verlag, 2001, pg. 128.

$5 \quad$ Ibid, pg. 198.

Ibid, pg. 132. Ibid, pg. 126. Ibid, pg. 126.
} 
stage of complete stagnation and urban housing development, controlled by an ultra-leftist ideology, once again emphasized extreme economy." ${ }^{\prime 9}$ Symptomatic of this was the closing of China's State Housing Administration in 1967. For a combination of practical and ideological reasons, including the need to reduce the number of citizens on the state payroll, many city dwellers were dispatched to the countryside to feed and fend for themselves. State investment in cities, such as it was, tended to be directed to inland districts and investment in infrastructure - geared to industry -- was largely made between rather than within cities.

Having dropped precipitously from 1966 to 1970, state investment in housing picked up with the Fourth Five Year Plan (1971-75). But while the volume of construction increased, investment in housing as percentage of overall capital construction never reached the level of $9 \%$ it had in the First Five Year Plan. Indeed it dropped as low as 2.6 percent in 1971. Experiments with high-rise housing in this period, ensembles of which were constructed in crowded eastern cities including Beijing and Shanghai, reflect, among other things, efforts to preserve arable land around cities. ${ }^{10}$

\section{Housing in the Reform Era}

Inaugurated in 1966, China's Cultural Revolution officially ended with the death of Mao Zedong in 1976. From a policy perspective, however, its influence was

9 Lu Junhua, Rowe, Peter G., Zhang Jie, Modern Urban Housing in China, 1840-2000, Munich, London, New York; Prestel Verlag, 2001, pg. 170.

$10 \quad$ Ibid, pg 173, 180. 
felt until the introduction of reforms in 1978. What we refer to as the Reform Era (or the era of Reform and Opening $U p$ ) began with ratification of a new set of policies championed by Deng Xiaoping.

Where the construction of urban housing is concerned, we might divide the Reform Era into 3 periods: 1978 to '92 (when Deng mad his trip through the southern part of the country), '92 to 2000, and 2000 to present. The period from 1979 to 2000 was largely characterized by the construction of walk-ups (although a number of high rises were constructed). As the country focused on providing modern housing to alleviate housing the shortages, the state experimented with allowing enterprises and individuals to invest in housing. This was followed by the period of the so-called "Socialist Market Economy", from 2000 to present. Housing in this period consists primarily of high rises.

4. Walk-ups in the Early Reform Period

Under Deng Xiaoping the central government again attempted to address both the supply and condition of housing in cities, where residential densities were extremely high and services in short supply. A national survey of housing in the mid-1980s indicated that only $24 \%$ of urban units in China had their own toilets and fewer than $60 \%$ had running water within the unit. ${ }^{11}$ Along with investment in infrastructure, dilapidated housing in the core - both ensembles of laneway housing and large pockets of self-built housing - were replaced with

11 Lu Junhua, Rowe, Peter G., Zhang Jie, Modern Urban Housing in China, 1840-2000, Munich, London, New York; Prestel Verlag, 2001. Pg 228 
new housing to which displaced residents were given provisional title. Initially a number of the cleared parcels - both in the core and on the near periphery - were built out with housing that closely resembled danwei housing, namely walk-up apartment blocks. Indeed a significant amount of this housing was initiated by work units, which were encouraged to be more entrepreneurial at the time. The term "chai qian" is used describe to the process of demolishing

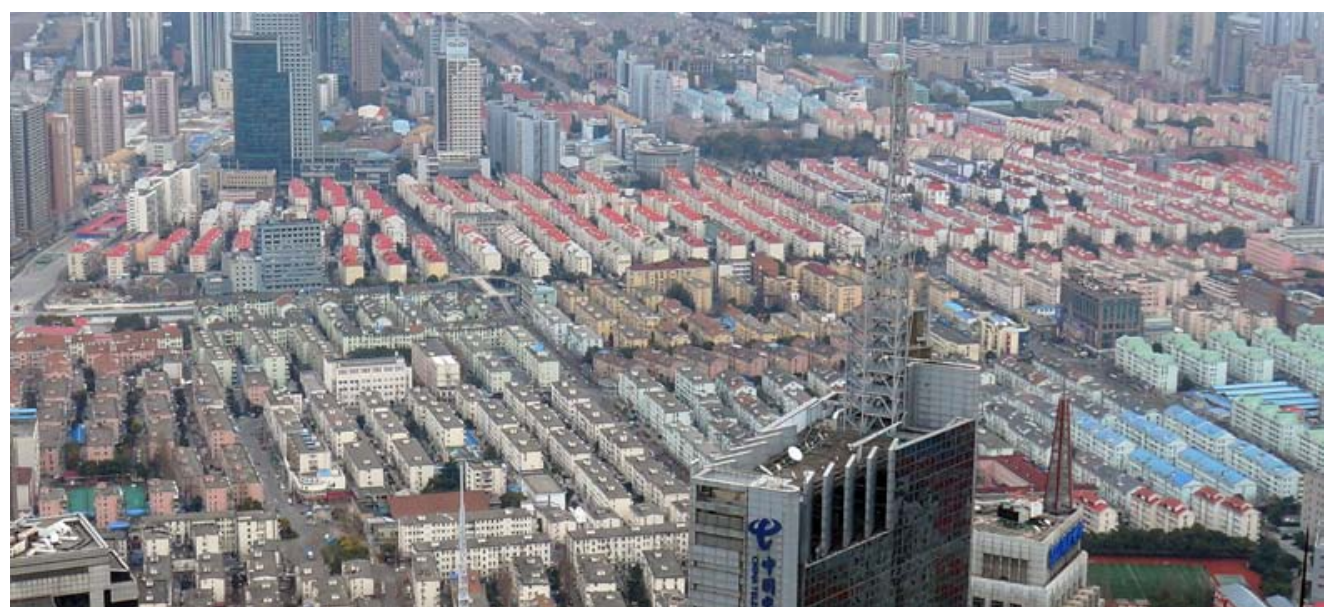

Figure 1.7 Photograph of remaining walk-up apartments in Shanghai. View is from Jin Mao Tower

and replacing units. We should also distinguish between chan quan, or "right to own" from shi yong quan, or "right to use," bearing in mind that ownership applies only to the unit, and not the land on which it sits. A "right to own" dwelling must have its own bath, toilet, and kitchen. A "right to use" dwelling, by contrast, typically shares services (bath, toilet, and/or kitchen) with other units. Given the preponderance of shared services in urban housing, most units constructed before 1980, fell under the "right to use" category and therefore 
were not available for ownership. "Right to own" units were largely only available in newly constructed buildings.

These apartments are typically 6 stories in height, and, consistent with tradition, buildings were organized in east-west rows to ensure that the main rooms faced south and units benefitted from cross ventilation. Built in the ' 90 s these were a inexpensive building method to quickly construct high density housing. The ground floors of a number of these buildings have been retrofitted to include small shops.

5. Tower in the Park Ensembles

Not only have size and status of China's cities changed but their form is changing rapidly. Most salient is the spate of high-rise towers that have appeared in the last twenty years. Less exterior servicing infrastructure was required (such as pipelines). ${ }^{12}$ In Shanghai alone some 20,000 buildings over eleven stories have been constructed since 1990 . While high-rise urbanism is epitomized by the super-tall office towers of the city's Pudong New District, the bulk of buildings over eleven stories are residential. Prior to 1990 very few residential buildings were higher than six stories. To increase living space in a country with limited land space and a large population, the high rise approach, was deemed most viable solution to for housing in urban areas. ${ }^{13}$ High rise developments also tend to require less infrastructure (e.g., pipes) to service.

$12 \quad$ Ibid, pg 181

13 Zheng Naigui \& Hu Huiyuan. "Our Opinion on High-rise Residential Buildings." Journal of Architecture 3 (1981); 40-42 
China has dealt with the provision of housing by applying simple templates. Both in the core and on the periphery, much (if not most) housing constructed in the past twenty years consists of repetitive high-rise housing blocks. No doubt this broad-brush, 'one-size-fits-all' approach to housing reflects topdown planning, the rising cost of land, and the need for efficiency in the face of

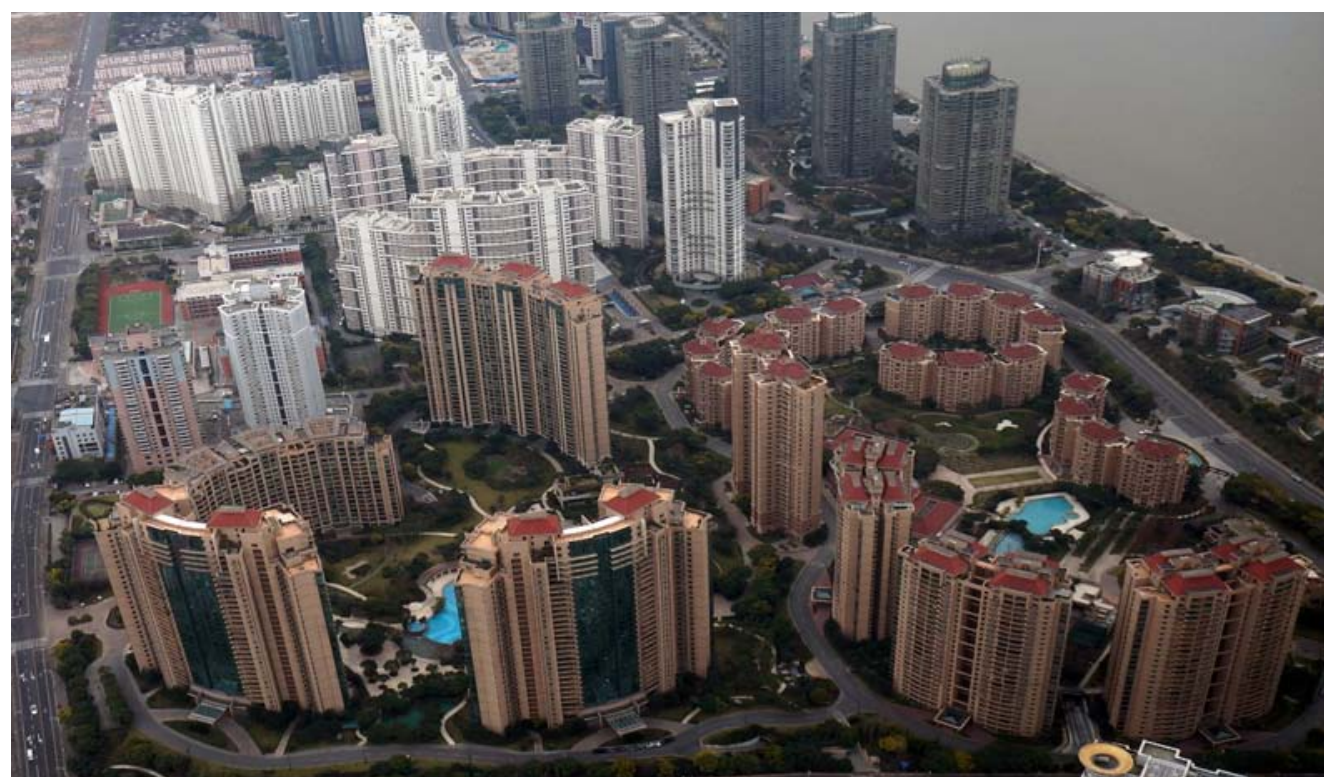

Figure 1.8 Photograph of new tower in the part developments. View is from Jin Mao Tower

the extraordinary pace and scale at which cities are transforming. As a result, housing appears more an expression of expediency than of the social, historic and cultural context of China. Nor does the design of housing reflect or respond in any obvious way to the complex social dynamics of migration.

Of particular concern is the possibility that the demographic profile of those migrating to cities in the next twenty-five years will be different than the recent wave of migrants. For a variety of reasons new migrants may not find it as easy to adapt to new environments and lifestyles. Being less skilled and educated than the previous cohort, housing may play a more strategic role. The next 
400 million may be better served by something closer to the informality of an "arrival city" than by rigid, tower-in-the-park compounds. Considering how best to house this group presents the opportunity to explore options, in particular indigenous Chinese approaches like the Shanghai lilong.

The rapidly emerging middle class is obviating the need for so-called transitional housing. The assumption is that the possession of the housing unit alone is sufficient to effect the transition. Title to a unit whose value is likely to increase is tantamount to a windfall capable of catapulting the rural poor into the ranks of the urban middle class. As such, units must be as generic and fungible as possible. Their primary value is as commodities to be traded. Left out of thie equations, is the ability of migrants with no education to maintain a middle class housing unit. Much is at stake. If China gets it wrong it risks social unrest. There are, however, also historical precedents to one-size-fits-all approaches to housing in China.

\section{Housing suitable for Migration}

Housing represents an important link between the individual and the larger world. The nature of the thresholds between the private and public realms affects how one accesses and engages the larger built environment. Migrants moving into the city must forge new spatial relationships, habits and identities. Dong Jie describes identity construction in three basic parts: construction in social practice, playing complex and multiple identities, and the imposed identity of 
others by interaction or assumption. ${ }^{14}$ Migrants who were previously isolated in rural areas must adopt new identities. The location, shape and adaptability of the environments in which they reside affect their ability to change or to absorb new ideas. Migrant housing is especially important in China because of the huge volume of people moving into cities and the scale of new residential developments. A study of established forms of housing for migrants in China may give us some clues as to how best to design for them.

Housing requirements for rural-to-urban migrants are different than those for established urban dwellers. While having access to a unit whose value is likely to increase and which can be traded in the marketplace will, in the long run, do much to lift migrants from peasantry to the middle class, the lifestyle change may be so drastic as to be alienating from the dweller's perspective. Within their new home, the migrant may feel trapped in places they don't understand. While this may be a generational thing, many migrants are illiterate, and lack the skills required to secure stable employment. Flexible, transitional space enables them to keep their rural habits while they acquire new habits in an urban setting. The housing to which these newcomers are directed should be designed to be able to evolve with their changing circumstances.

Vernacular forms of architecture typically evolve over time as a result of living patterns. A "vernacular" approach to housing for migrants may be

14 Jie, Dong. Discourse, Identity, and China's Internal Migration: The Long March to the City. Bristol: Multilingual Matters, 2011. Print. 
more appropriate than the current, top-down approach. With some significant exceptions, housing for new urban arrivals in China is pre-planned and generic enough to be palatable to the marketplace. Can the idea of pre-planned, topdown, market-friendly housing be squared with the bottom-up flexibility and adaptability we associate with vernacular architecture?

\section{Conclusion}

As the Chinese economy matures and diversifies, migration patterns change as does the profile of migrants. Since economic reforms were initiated in the late 1970s some 300 million Chinese have moved into cities. In the course of three short decades the rate of urbanization in China has increased exponentially: from roughly 20\% in 1980 to 54\% today. This so-called "great migration" has not only transformed cities, but altered the social, cultural, economic, and physical character of the country as a whole. Cities are expected to receive and additional 400 million migrants in by 2050 . Included in this wave will be many of the socalled floating populations. Exchanging rural for urban status, as well as the circular and continuous movement for a permanent settlement, the migrants will forge new identities in the cities in which they settle. The following Chapter discusses China's current targets of migration and their approach to housing the next 400 Million. 


\section{Part \\ China's Approach to the next 400 Million}

\section{Introduction}

The focus of this thesis is housing. Among the issues at play are who provides the housing to accommodate the influx of residents, the cost at which its made available, and the location of housing relative to transportation, jobs and other economic opportunities. As an architectural designer, however, I am particularly interested in the form this housing takes, and in particular how well suited it is to the intended demographic. The thesis questions the extent to which the design of housing may help or hinder the process of assimilation, and how adaptable it is to the changing terms of reference under which it might be expected to operate.

Over the past several decades the government has relied on the marketplace to produce housing - a radical shift from the approach taken under Mao Zedong. Municipal governments often divide up developable land into six hectare blocks, which they lease to developers. Cities rely on these developers to lay out neighborhoods, finance and construct housing. While the housing produced reflects market demand, the marketplace cannot provide for some sectors of the 
population. By understanding the limits of current modes of housing production, this chapter focuses on the demographic characteristics and needs of the next wave of migrants.

\section{Targets of Migration}

Along with the myriad forces that push people from one location or pull them towards another, several other factors are at play in China. Expanding cities annex and absorb villages on their peripheries. As rural land is converted to urban uses, residents are relocated to make way for higher density development. Rural residents, those with rural hukou, collectively own their land and transactions are brokered through village councils. The process of annexation and relocation is complicated, contentious and expensive. In principle, displaced households are offered a cash buyout and up to three apartments each in newly constructed housing - typically high-rise slabs on the periphery. Protests over illegal land seizure and unfair compensation, however, occur regularly. Because deals are often negotiated in secret, disagreements arise over the distribution of compensation among claimants.

When rural land is reclassified as urban, development rights are reassigned to the state (typically the local municipality). Reclassified urban land is typically leased in large parcels to developers. The developers construct new units to sell in the marketplace. Leases on land for residential development are typically for 70 years. Profit from land leases funds social services and land is used as collateral to procure loans for infrastructure projects. The cost and complication 
of obtaining and clearing land increases the cost of development and inflates the cost of housing.

Beyond the expanding peripheries of cities, the government is also attempting to move people off of agricultural land - significant amounts of which have been taken out of cultivation over the last several decades. The limited scale at which farming is done in China coupled with the equipment farmers have at their disposal can make it less profitable for farmers to plant crops than to look for temporary work in factories. Moreover, much of the land designated as agricultural is not suitable for cultivation beyond a subsistence level. Policies call for such land to be reforested.

Moving people off of the rural land and promoting urbanization has many benefits for the government and the country. The massive movement of people into cities that began in 1979 has been relatively well managed by policies and incremental reforms. ${ }^{1}$ But despite the fact that privatization of the property market has helped lift more than a half a billion people out of poverty, ${ }^{2}$ China's next 400 million rural-to-urban migrants may be facing a different set of challenges. As it matures, the economy will shift from labor to services, changing the terms of reference under which new migrants will transition to urban life.

$1 \quad$ "Urbanization and Economic Growth." World Bank Group. Web. 11 Feb. 2015. <https://www.worldbank.org/content/dam/Worldbank/document/EAP/China/Urban-ChinaSRs1-3.pdf $>$.

2 Ibid, 
Urbanization and the new market economy have created a sizable middle class in a few short decades. However, those forced off their land in the future may not fare as well as the pervious cohort, for whom university degrees were frequently a pre-condition for changing hukou. Many of those being forced off their land are warehoused in less-than-favourable locations with respect to economic opportunities; nor do they have the skills required to participate in a mature urban economy. Urban apartment living -- even when the unit is fully owned isn't sustainable in the absence of income. A steady income is necessary to cover household expenses (utilities, maintenance, furniture, food), and disposable income is key to the domestic spending that makes the middle class valuable for an economic system. Without regular income, new migrants will need to rely on the government for support.

\section{Changing Hukou}

China's hukou system traditionally restricted rural-to-urban migration, in part to manage demand on social services. As it stands, access to social services is tied to one's hukou status, thus creating a social gap between local urban hukou holders who are entitled to services and migrants with a rural hukou who are not. Despite this, many rural hukou holders move to cities temporarily to work in factories and on construction sites. Often having left their children to be raised by grandparents in the villages where they have access to schools and health care, these workers travel between rural villages and temporary dwellings on the periphery of cities. While uprooted from the farm, these "floating populations" are unable to establish themselves in the city. 
China is, however, experimenting with different approaches to hukou reform to make it easier for rural residents to permanently resettle in cities. As such, unskilled rural workers may constitute a significant percentage of the next 400 million, and will come to the city with fewer skills and resources than the previous cohort.

Hukou reform will involve monumental costs for the government. An estimated 200 million people in China reside in cities without local hukou (exact numbers are difficult to confirm as this demographic does not appear in official census data). If they are allowed to officially change their status municipal governments would assume responsibility for social services for these individuals and for the family members they bring with them. Designing a social system that can effectively support population increases is an ongoing challenge.

Fewer social services are available in rural areas than in cities. In principle the diminished quantity and rudimentary quality of services to which rural residents have access is offset by the fact that they have title to the land they occupy. While urban status would afford rural-to-urban migrants access to higher-quality health care and superior schooling for their children, many rural residents are wary of surrendering the only thing they possess, namely land.

Several cities have pioneered land reforms to address problems created by the hukou system, offering urban status to rural residents in the same province. They have experimented with relocating rural migrants into urban areas by building subsidized housing - a relatively rare commodity in China since the 
shift away from state welfare in the late 1970s. ${ }^{3}$ This system allows migrants to continue to access rural land for three years after receiving an urban hukou, in effect easing the transition from rural to urban life.

It can be difficult to predict the outcome of various approaches to hukou reform and the success of a program in one place does not ensure success its elsewhere. Constructing housing and relocating migrants into urban areas in advance of economic opportunities and a robust system of social supports can place extraordinary pressure on cities. While access to (affordable) housing is a key challenge, it is only one of many that rural migrants face. Moreover, the nature of the benefit one receives from housing depends on where it is located and how it is designed.

Access to affordable housing, while necessary, is not sufficient. Depending on its location and design, housing can help or hinder the transition from rural to urban life; thoughtful design can, to some extent, compensate for a less than favorable location. More than mere shelter, one's residence is a node in a network of connections, both physical and social. Arguably the housing to which many low-income migrants are directed is too rigid. It lacks the flexibility necessary to support informal economies and the formation of social networks.

3 Beginning in 2010, China embarked on the construction of some 36 million subsidized housing units. 


\section{Housing Available to Migrants}

The government's push to open the housing market and promote home ownership both supports the economy and removes the burden of constructing and maintaining housing from the government. It represents a radical shift from housing as a form of "in-kind welfare," as it was in the first several decades of the Communist Era. High rates of home ownership in tandem with increasing property values has contributed significantly to the formation of a middle class. Increasing property values, however, create challenges with respect to accommodating the next 400 million. In response to this China is undertaking the construction of some 36 million "public" housing units. ${ }^{4}$ These units will not only be made available to low-income residents at below market rates (with variety of tenancy options), but the construction of these units will provide jobs for unskilled workers, including potential residents. Moreover revenue from the leases on the land on which this housing is built will help offset the cost of social services for new migrants.

To purchase property one must possess have a local hukou, making the property market unavailable to migrants who are unable to change their hukou status. ${ }^{5}$ Affordable housing is offered through government subsidies to young workers with a university education or high skill sets that might be forced (or otherwise opt) to settle in a different city because of the high housing prices. This housing

\footnotetext{
$4 \quad$ Areddy, James and Davis, Bob, "China Pins Hopes on Public Housing," Wall Street Journal, Dec. 30, 2011

5 People who do not have a local hukou must have paid taxes to the municipal tax bureau for the last five years to qualify as homebuyers. See "Should Home Buying Be Tied to Hukou?," Beijing Forum, NO. 13 March 31, 2011, http://www.bjreview.com.cn/forum/ txt/2011-03/27/content_346980.htm, accessed April 3, 2015
} 
is usually used by graduating students who have been recruited by employers and have work permits or opportunity to change their hukou. Cities are eager to attract young workers for their skills, their willingness to spend in support of the consumer economy, as well as to support the aging population.

Temporary housing - e.g., housing occupied by temporary workers -- is built and controlled by companies and made available to employees. This housing is often small, cramped, barrack style living with communal amenities. Temporary housing is the only formal type of housing available to migrants moving to urban areas without a local hukou.

China's focus on developing a middle class coupled with the role housing plays in the formation of the middle class strongly influences its approach to housing. Transitional housing, designed to better enable migrants or low-income residents to transition into a new area, is virtually unknown. On the assumption that migrants will transition so quickly into middle class (and that access to a market-worthy housing unit will play a significant role in that transition), even subsidized housing is built according to "generic" marketplace templates.

Given the potential differences between the previous cohort of rural-tourban migrants and the next 400 million, it may be prudent to explore other approaches to housing for low-income residents. Rather than looking to nonChinese precedents, the following chapters compare the lilong, a form of housing 
associated with China's Treaty Ports developed specifically for migrants, with the current, market-driven approach of one-size-fits-all housing. 


\section{Part Learning from the Lilong}

As a housing type, the lilong originated in the mid 19th century when China was forcibly opened foreign trade. Enclaves of lilongs were constructed for successive waves of rural migrants as the volume of trade and other economic activity increased in China's Treaty Ports. With its the roots in clustered housing found in cities in southern China, lilong housing might be characterized as a cross between western row housing and traditional siheyuan (or courtyard) housing. Lilong enclaves consist of rows of south-facing houses separated by tight, eastwest alleyways and connected by larger north-south alleys. Aggregations of lilong housing were frequently enclosed within blocks and accessible thorough periodic openings in the surrounding buildings. Hidden inside the block, however, vibrant communities thrived.

The housing type most often associated with the lilong is the shikumen, or "stone-gate" house. Attached on two sides, each of these multi-story dwellings incorporates a compact, south-facing exterior space - equal parts front porch and forecourt. This courtyard is embedded into the house and walled off from 
the laneway with a gate. The name shikumen derives from the elaborate stone surrounds that frequently enframe these gates.

Incorporating aspects of both the hutong and the siheyuan, this form of housing expedited the transition from rural to urban life in the foreign concessions of China's Treat Ports, most notably Shanghai. Being extremely flexible, the layout of the lilong allowed for additional rooms to be built. Separate back entrances enabled portions of houses to be rented out while south-facing courtyards could be used as gardens, work spaces, or be enclosed to accommodate additional interior space.

The lilong template was also applied to neighborhoods of larger houses. Compounds of so-called "garden style" lilongs were built for wealthier residents as standards changed and smaller units were handed down. While the overall organization remained the same, both the houses and the south-facing courtyards

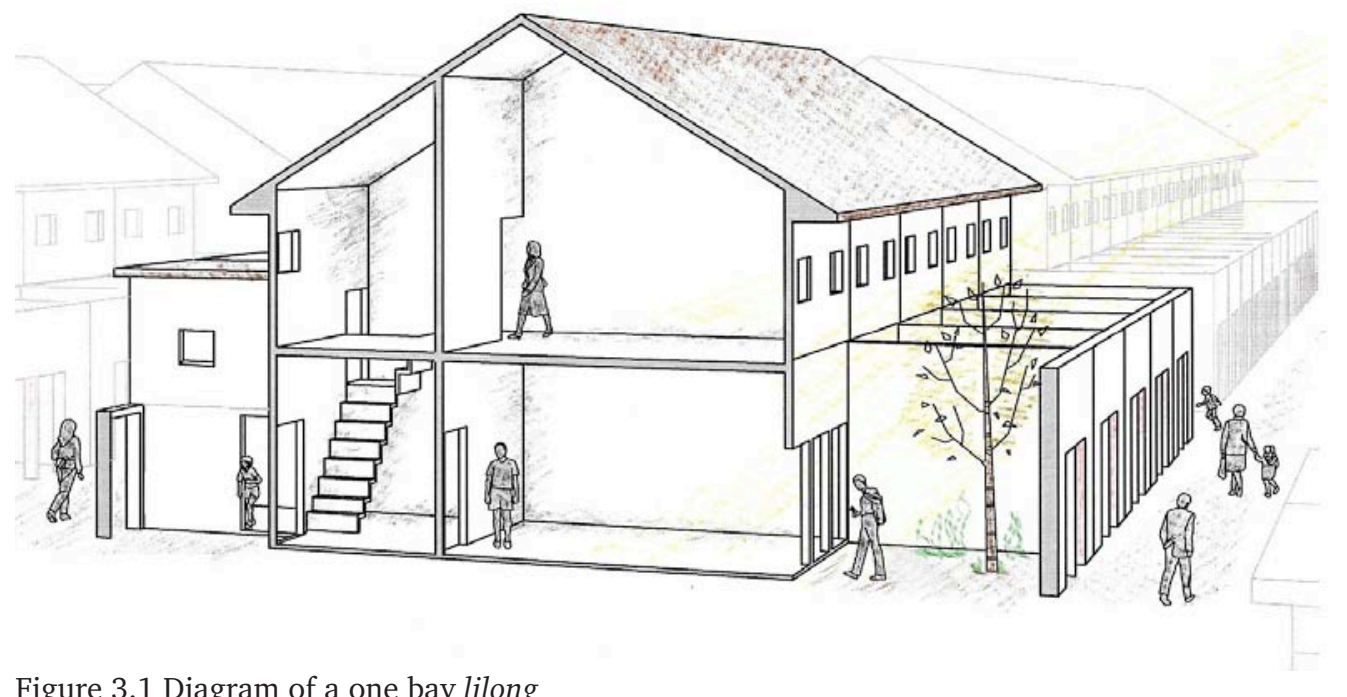

Figure 3.1 Diagram of a one bay lilong 
of the garden-style lilong were larger. The laneways separating rows of houses were also significantly wider.

Fig 3.1 illustrates a typical row of two-story, one-bay shikumen houses along an alleyway. It demonstrates how tightly individual dwellings were connected into the neighbourhood fabric. The small, enclosed courtyards at the front of each dwelling enabled daylight to penetrate the first floor; it also created a semi-private barrier between the public alleys and the living space within units. Activities preformed in courtyards frequently spilled out into laneways, which functioned as communal courtyards. The result was a blurring of the boundaries between private spaces, creating layers of semi-public community space. It is not uncommon to see residents napping, cooking, or hanging their laundry in these spaces. Fig. 3.2 shows a washbasin projecting into public lane way.

Like the spaces within houses, the vibrant alleyways of the lilongs were flexible: they could be simply built, and easily inhabited as needed by migrants. Moreover, the lilong's network of semi-public and semi-private spaces supported aspects of village life, easing the transition from countryside to city. Figure 3.3 shows an entrance to a lilong enclave used for drying laundry, posting public announcements, and storage. As a vernacular form, the lilongs are not only historically significant, but have long been instrumental in facilitating the process of urbanization.

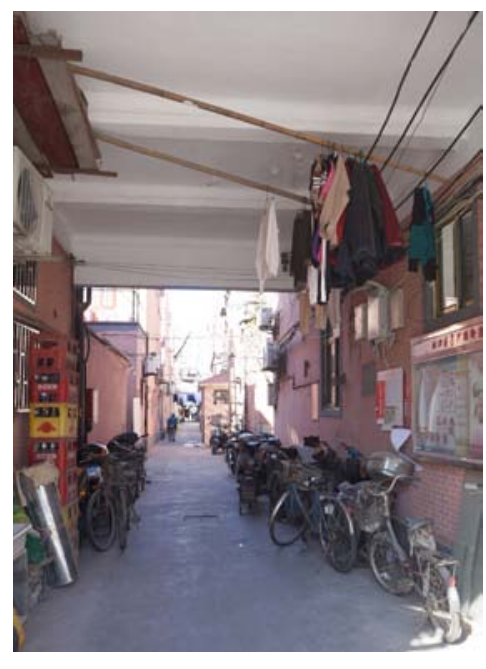

Figure 3.3 Photo of entry to lilong enclave.

The articulated, nuanced network of spaces associated with the lilong is largely absent from current mass housing developments, nor are the units in housing 
towers nearly as flexible with respect to the way they can be used or the living arrangements they can accommodate. The tight network of spaces created by the lilongs differs dramatically from the scale and quality of the large open spaces in new developments. The quality of space, in turn, affects the sense of community and the way that spaces are used. As additional stories are added, the spacing of buildings increases to allow daylight into every unit. Figure 3.4 shows the relationship between height and distance between buildings. The intimate semi-public spaces that was very useful for the migrants living in the

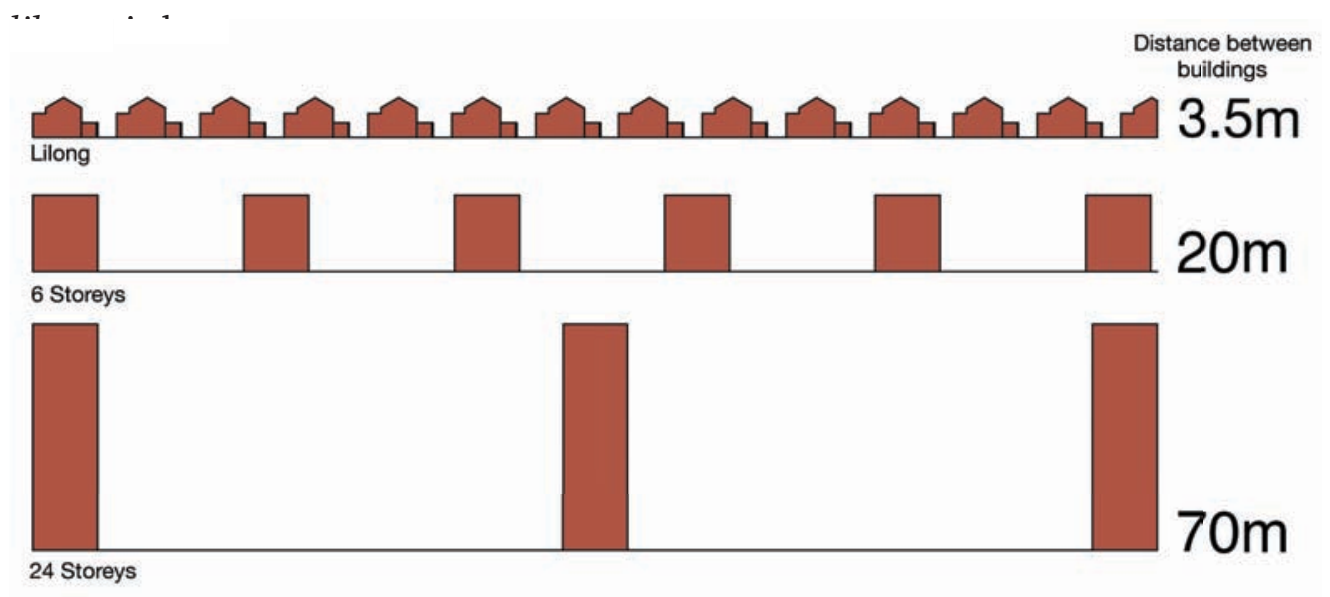

Figure 3.4 Diagram of distances between buildings based on building height and sun angles.

While shikumen houses were built as single-family dwellings (the number of bays reflecting the overall size of the household), units were frequently subdivided. In the communist era, multiple families were assigned to the same house, as many as one family per room. Fig. 3.5 shows the growing density inside a lilong.
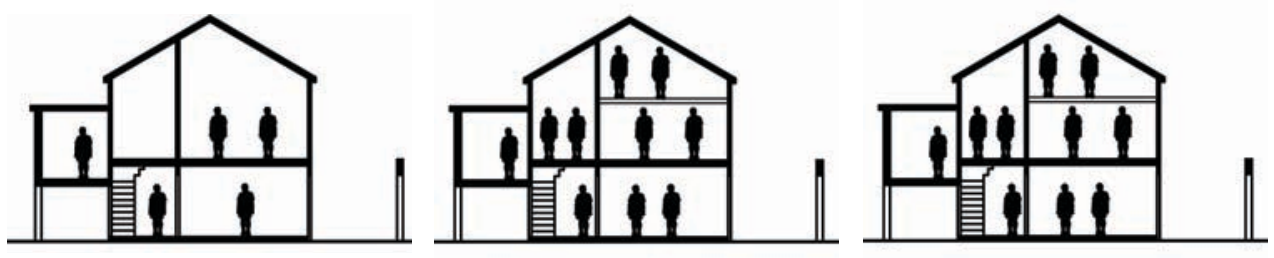

Figure 3.5 Diagram growing densities inside the lilong 
To accommodate the increasing number of families tall rooms were divided into two floors; shelters were built on the rooftops, and both courtyards and light wells were enclosed to create additional rooms. Residents relied on common areas for storage and cooking, as the alleyways became tighter as more private functions were perfumed outside to compensate for the lack of interior space. The lilong areas became slum-like because of their extremely dense living conditions. ${ }^{1}$

The extremely cramped in poor conditions in which many residents were forced to live explains why Chinese cities have largely turned their backs on the lilong. Given the opportunity most of the residents remaining lilongs would be more than happy to put the past behind them and relocate to a new unit in a tower ensemble. Unlike the lilong, Reform-Era tower developments suffer from an abundance of space. More to the point, units in these ensembles are likely to increase in value.

Figure 3.6 highlights the remaining pockets of lilong housing in a portion of Shanghai's Honkou District, formally part of the American Concession. While the tower apartments with which the lilongs are being replaced provide modern amenities, they do not support community in the same ways as the older laneway neighborhoods.

1 Liang, Samuel Y. Remaking China's Great Cities: Space and Culture in Urban Housing, Renewal, and Expansion. Routledge; 1 Edition, 2014. Print. Pg 23 


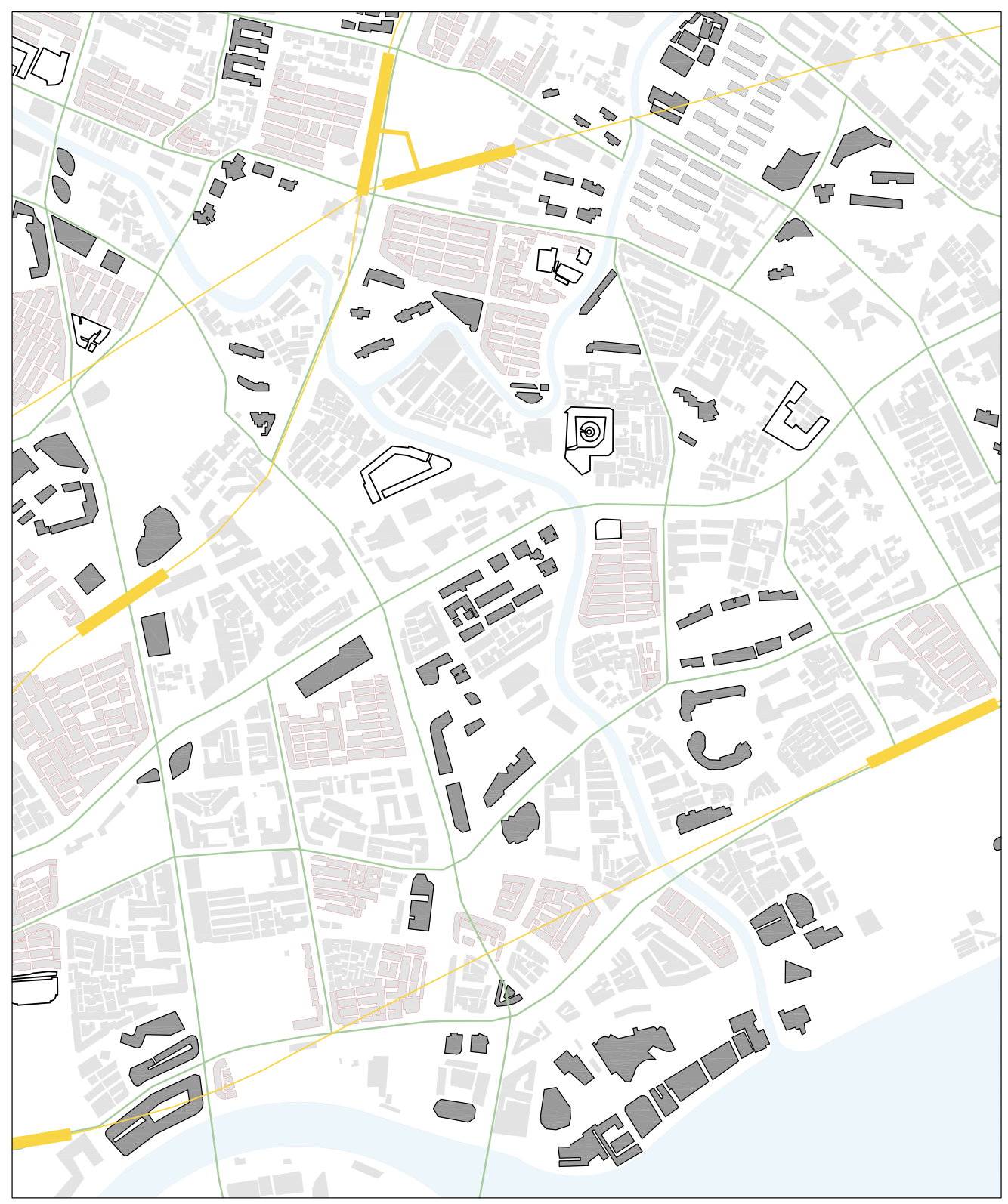

Figure 3.6 Map of remaining lilong enclaves (shown in red) in Shanghai's Honkou District

To be become a part of the new housing market, many lilong ensembles would require extensive renovations, likely rendering them more costly than what they could sell for on the market. Together the high cost of renovations, the relatively low densities at which they are built, and the high value of the land 
on which they sit makes it more economical to replace lilongs than to renovate them. Market density that supports land values at a middle class rate typically includes 1.5 times more units per acre than the lilongs. ${ }^{2}$

While the tight ensembles of lilongs in Shanghai's Honkou District may not be successful in transitioning into the new market, they successfully supported the transition from rural to urban life for many generations of migrants. When planning for the next 400 million, it may be prudent to consider forms of housing that are as flexible and adaptable as the lilong.

I believe we have much to learn from the lilong. Although its impossible to predict what will happen to the urban housing market (as middle class housing preferences evolve and 70-year land leases expire), we should deploy flexible strategies that are able to adapt to different living standards. Given the volume of housing that is being constructed in China at present - including the 36 million units of social housing - design matters. Today's housing will determine China's future. Housing built at such a large scale will fail or succeed in a big way.

Typical UPA of a lilong is 85 


\section{One-Size-Fits-All Critique}

Accumulated shortages, rapid urbanization, and the need to replace substandard housing have resulted a significant and sustained demand for new housing in China. In great part the country has responded with an expedient, "one-sizefits-all" approach in the form of repetitive towers on large development parcels. This allows developers to achieve relatively high residential densities, realize economies of scale, and maximize open space on the parcels they build out. The vast majority of housing constructed in Shanghai in the last 25 years consists of high-rise slabs. Given the range of people a city as large as Shanghai, however, it's unclear how the same form of housing can work such a broad demographic range.

Lacking in education, skills, and limited in their employment prospects, ruralto-urban migrants are expected to participate in a consumer lifestyle that they are unable to sustain. Tower living represents one of the more drastic changes in what can be a sustained and difficult transition to urban life. The following case studies compare various approaches to mass housing with informal neighborhoods built by the migrants who inhabit them. 


\section{Tower-in-the-Park Approach}

Widespread acceptance of tower living in China reflects, among other things, a reaction to the extremely poor housing conditions that most citizens endured prior to the 1990s. In the Communist Era private space was a commodity available only to the rich. Multiple families shared the same small living spaces averaging of only $3.6 \mathrm{~m} 2$ per person. The ability to own and control one's residence was virtually unimaginable in China thirty years ago. For most Chinese, housing towers represent space, privacy and the opportunity to own. As all these are good things, towers are good. Approaching $20 \mathrm{~m} 2$ per person, the spaciousness of Reform-Era tower units also diminishes the need to use urban space as private space, mitigating the disadvantages of living high above the ground.

Housing slabs can be constructed relatively quickly and efficiently. Producing them in bulk on large development parcels decreases both the time it takes to bring new units to market and the cost to produce them. In principle the limited availability of land in China necessitates high-density development, which, in current thinking, translates to higher buildings. The tower approach also enables

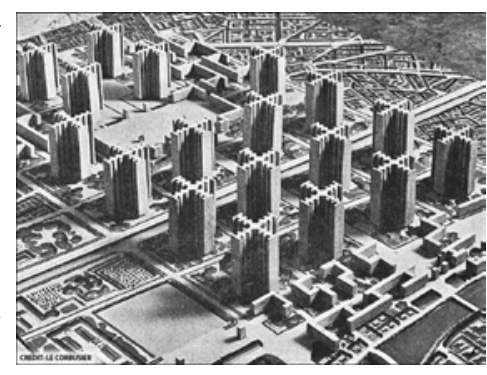
a larger proportion of the ground plane in each development parcel to remain open, which is widely considered to be a good thing - especially in relation to overcrowded hutong and lilong neighborhoods of the pre-Reform era. On the downside, however, large parcel developments often isolate residents from commercial areas, and fewer roads mean wider roads that isolate ensembles from each other.

Figure 4.1 Le Corbusier's Radiant City

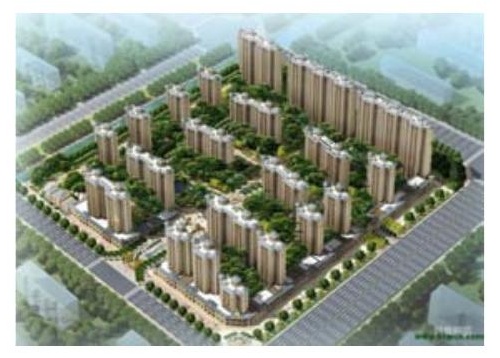

Figure 4.2 Rendering of a Tower in the Park Development 
To a significant degree, positioning of slabs in residential tower is determined by solar orientation. As each residential unit must each receive a minimum of 1 hour of sunlight on the shortest day of the year, buildings typically face south and are spaced to minimize the extent to which they cast shadows on each other. The repetitive pattern of towers and scale of open space in many Reform-Era complexes recall Modernist "tower in the park" proposals by Le Figure 4.3 Le Corbusier's Tower in the park Corbusier, Walter Gropius and others. Applied to social housing complexes in Europe and North America after WWII, the tower-in-the-park template proved problematic for families of limited means. Among the many issues at play were social isolation and limited opportunities for residents to adapt or transform their space.

boulevard

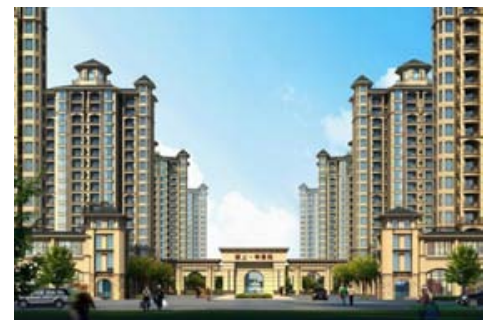

Figure 4.4 Tower in the Park rendering of entrance gate and towers

The Grands Ensembles constructed around Paris in the early 1960s are examples of large-scale, tower-in-the-park developments. They were constructed to replace substandard housing in the core, to accommodate an influx of urban migrants, and to increase the supply of housing adjacent to new industrial zones on the urban periphery. ${ }^{1}$ The configuration of these ensembles - from the layout of units to the position of buildings - was determined by a set of quantitative and technical guidelines. Social amenities, however, were frequently eliminated due to budget and space constraints. Equal parts practical and utopian, the grands ensembles represented an attempt to determine social life through state policies. They were designed in a period characterized by complicated relationships 
between industry, the government, and social commentators. While critiques of the grands ensembles center on the social life within them, it may be relevant to consider the impact of the physical environment on the lives of the residents. Although specific policies (notably the "one child per family" rule) and a high level of government control make China unique, parallels may exist between the country's attempt to house migrants quickly and efficiently on the periphery and what was done in France in the post-war period. Isolating low-income, rural-to-urban migrants in highly structured environments may hamper the formation of social networks and new identities.

\section{Public Housing}

The Chinese government is eager to expand the middle class by way of increasing per-capita consumer spending. Home ownership, as noted above, is instrumental to the formation of the middle class, as is urbanization. Minxin Jiayaun, a housing complex in Chongqing, is a socially conscious example of a top-down attempt to promote the transition from rural to urban life. Forty million square meters $(10,000$ acres) on the outskirts of the city were divided into twenty-one parcels and developed as low-income housing. ${ }^{2}$ Profits made by leasing the land to developers were used to build subsidized rental housing. Farmers on the outskirts of the city surrendered their land in exchange for urban hukou and a cash payout or apartment. Renters have the option to purchase their units in five years. As part of the financing plan, however, a portion of the

2 Huang, Philip CC. "Chongqing Equitable Development Driven by a "Third Hand"?." Modern China 37.6 (2011) 
capital gains from the sales of these apartments is returned to the government to fund subsidized rental housing.

Despite the favorable terms, however, migrants are moved into what amounts to middle class housing without the means to support a middle class lifestyle. There are very few jobs for the migrants, who need to earn more than the temporary laborers (with whom they compete for jobs) to be able to maintain their apartments. While Chongqing has training programs to support rural-tourban migrants so they can move from manual work to skill-based work, only one third of the migrants benefited. ${ }^{3}$ Household amenities such as washing machines and stoves often sit unused as they are too expensive to maintain. This results in urban living with rural habits such as washing clothes in a nearby river.

Despite being labeled a success,${ }^{4}$ the Chongqing experiment has provoked Figure 4.5 Photo of mixed reactions from its residents. The lack of jobs and occupations often make towers in Chongqing people feel useless. Complaints of being stifled to death by the secluded living conditions are common. While the development helped to create equal living spaces for all, it ignored key social and emotional aspects of transition from rural to urban life.

The new town of Huaming, the product of an effort to consolidate farmland in

$3 \quad$ State of the World's Cities, 2012/2013: Prosperity of Cities. New York Pg. 72 4 Miller, Tom. China's Urban Billion: The Story behind the Biggest Migration in Human History. London: Zed Books ;, 2012. Pg 79 
order to increase agricultural productivity, also claims to have given farmers a new life at no cost. Prior to consolidation, 41,000 people lived in 12 small villages dotted across 60 square miles, most of which was farmland. The government demolished and amalgamated the villages into a single new "city": a housing complex with modern living amenities. While close to an industrial zone on the outskirts of Tianjin, few of the residents have the skills necessary to benefit from opportunities to which they were given access.

"Even when they can get the well-paying menial jobs of $\$ 150$ a month, residents overwhelmingly said this barely allowed them to make ends meet. Day care costs $\$ 100$ per month per child, which would take a third of an average couple's salary. Unlike in the villages, many families do not live near one another, making it hard to leave children with their grandparents." 5

Signs of social dysfunction abound. Only a small fraction of the young people, who wile away hours in internet cafes and pool halls, have jobs. The elderly are forced to take menial work to make ends meet. Neighborhood and family structures have been damaged. The situation in these new towns contrasts with the makeshift housing where other migrants live.

Many of those are comprised of farmers who chose to leave their land for jobs in the city. Although cramped and messy, they are full of vitality and upward mobility, said Biao Xiang, a social anthropologist at Oxford University who has studied migrant communities.

5 Johnson, Ian, "New China Cities: Shoddy Homes, Broken Hope," New York Times, Nov. 9, 2013 
"These migrant neighborhoods in big cities are often called slums, but it's the new resettlement communities that will be harder to revive, partly because they are not related to any productive economic activity," Professor Xiang said. "And the population tend to be homogeneous, disadvantaged communities."

Rather than being liberated through access to the city, many residents feel trapped and their lack of mobility creates the feelings of despair associated with large-scale housing projects in North America and grands ensembles. ${ }^{6}$

\section{Critique}

The rapid transition of the market and speed at which the residential towers are being built leaves little time for debate over cultural and community values being lost or produced. However, given the fate of many tower-in-the-park complexes in North America and Europe, it's not difficult to imagine that problems could arise. China's predilection for high-rise ensembles has been greatly influenced by the approach taken in Singapore and Hong Kong. Urban planner Joe Berridge observes that while tower complexes in these cities break all of Jane Jacobs' rules for successful communities, they have been successful. The question is the degree to which these successes can be translated to China. ${ }^{7}$

Migrants have been moving into the city at their own rate ignoring the hukou. As they arrive, they create informal arrival cities. This cohort (liudong renkou)

\footnotetext{
6 Johnson, Ian, "New China Cities: Shoddy Homes, Broken Hope," New York Times, Nov. 9,2013

$7 \quad$ Berridge, Joe, Lee Kuan Yew's Singapore - Another Way of City Building, March 23, 2015, http://www.urbanstrategies.com/blog/lee-kuan-yews-singapore-another-way-of-citybuilding/. Accessed March 25, 2015.
} 
frequently rents housing within what are known as "rural-urban transitional zones" within the municipal boundary. These are lands whose status has changed from rural to urban. Urban residents with rural status have more control over this land and often construct rental housing (or rent out houses they are no longer occupying) to migrant workers.

Housing created in the informal cities is inherently vernacular, as the migrants build exactly what they require. Vernacular architecture generally reflects the needs and characteristics of those who build it. The mass apartment tower approach has the opposite effect; residents are forced to adapt to the housing type. Particularly for low-income residents, the failure of mass housing or towers was a function of the inflexible standards and strategies that determine how people should live. Mass housing privileges the structure of buildings over the requirements of residents. Migrants moving into cities, however, need the flexibility to adapt and connect into the larger social framework of the city.

\section{Informal Arrival City - Liu Gong Li}

The term "arrival city" is typically applied to informal developments on the outskirts of cities; migrants move here to live until they can afford to move into the city proper. An arrival city is a place of constant movement and change. In China such places are associated with the floating populations. While within striking distance of jobs, inhabitants of arrival cities maintain a connection with the places from which they've come. As cities expand and absorb these informal developments, they either become part of the city or are demolished for market 
housing. Although many of these cities look like slums, their inhabitants are no means without hope or prospects.

Arrival cities offer more opportunities than rural areas, even though living conditions can be less than adequate. Here both the architecture and social networks are established based on need and lifestyles. Inherently flexible and constantly adapting, spaces that can be used as migrants require. Lacking in infrastructure such as sewage as electricity, it can be both difficult and expensive to connect informal developments to the rest of the urban fabric. While successful in the short term, the ad-hoc nature of their form compromises their longer-term sustainability within a mature urban environment.

\section{Peri-urban Villages}

Peri-urban villages are a type of informal settlement. As cities grow and surround rural villages, some villages refuse to relinquish their communal land rights. Rather than selling to developers, villages develop their own land - frequently in ways that differ significantly from what large-scale housing developers produce. Peri-urban villages generally consist of eight storey buildings built on the typical rural village grid with narrow lanes. It is estimated that nearly 3 million of Beijing's 7 million migrant workers live in villages like this, some 600 of which have been swallowed up in the past several decades as the city has expanded. ${ }^{8}$

8 Miller, Tom. China's Urban Billion: The Story behind the Biggest Migration in Human History. London: Zed Books ;, 2012. 
Zhejiang, an urban village outside Beijing, began by renting out spaces to migrants moving to Beijing. In time, however, the village embarked on the construction of what are known as Dayuan, namely large single storey buildings with hundreds of units organized around a courtyard. What was once a village of 20,000 people now accommodates over 100,000 migrants. The continued informal development around Zhejiang was a result of entrepreneurial migrants making deals with the locals to build out village land, establish businesses, as well as attracting more migrants from their original villages. This created both a sense of collective urban and social progress and opportunities for individual gains. As the community, expanded, however, both social and civic spaces were increasingly lacking. While designed to accommodate the needs of migrants, it is also important that housing be designed to be able to transition to middleclass housing. Arguably this is also a shortcoming with the housing in both informal settlements and Peri-urban villages.

\section{Conclusion}

One of the main architectural critiques of the tower is its inflexibility. Its structure makes it difficult for the collective population to manipulate spaces in or around buildings as the need arises, something that is extremely important for a transition migrant population. The tower approach and mass housing is an expression of objective market data rather than subjective criteria. Although China, is looking to quickly transition migrants from peasant lifestyles into middle class consumers, the spaces to which they are directing migrants may 
be hindering the transition. The ambition of this thesis is to identify strategies ideally indigenous ones - that are both flexible to adapt to the changing needs of residents and to transition, with the residents, to a middle class standard. 


\section{Terms of Reference for housing the next "400 Million"}

\section{Project Background}

With a predicted 400 million people moving into cities within the next thirty years, the strategies that China employs to house low-income migrants will have a significant impact both on the ability of these individuals to adapt and on the long-term success of cities. As they settle in cities, these migrants will forge new identities and reconstruct social networks. Access to housing that is flexible, that promotes interaction, is able to adapt to inhabitants' changing needs, and is complimentary to the urban fabric is essential. The design portion of this thesis draws on traditional lilong housing to propose a flexible strategy that challenges China's current one-size-fits-all approach.

\section{Content}

Through the process of multiple design iterations, two prototypes were developed for the redesign of lilong housing. Among the issues addressed are efficiency of construction, market requirements, flexibility, adaptability, compatibility with established urban patterns and the potential to foster social networks. 


\section{Market Requirements}

China's default template for the production of housing, namely large ensembles of towers, is both economic and efficient. Alternatives to this approach must be simple and able to be constructed in high volumes. If the lilong were to be reintroduced, modifications may need to be made to the way in which units are constructed.
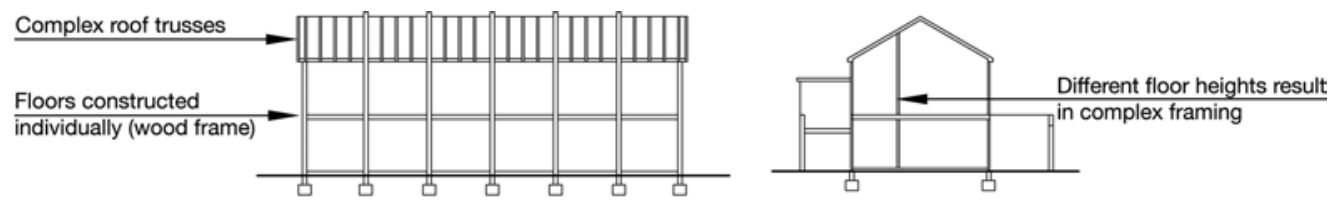

Lilong Structural Skeleton
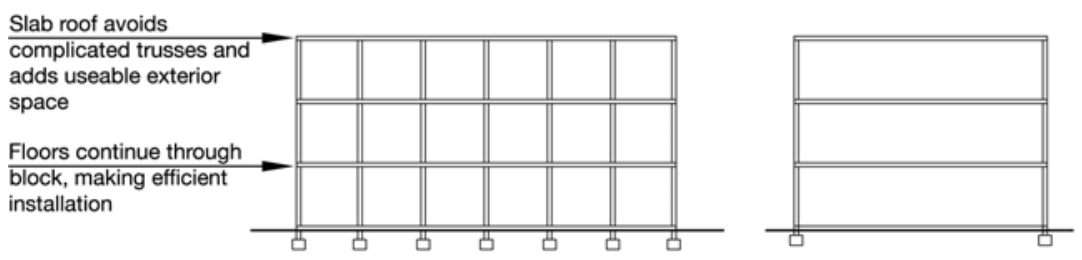

Column and Slab Structural Skeleton

Figure 5.1 Diagram comparing of lilong structure to and column and slab structure

The market demands dense living to keep housing affordable, to conserve land (China has a low ratio of land per person and arable land is especially scarce), as well as to reduce the negative environmental impacts of urbanization. Figure 5.2 compares a typical lilong of one-bay shikumen houses in Shanghai's Honkou District (see fig. 3.7) to current density standards for residential development. While the delta clearly indicates that modification are in order, the lilong is an extremely adaptable form.

Floor Area Ratio (FAR) describes the relationship between the total building area to the area of the site; the higher the FAR the higher the built density. Current 
standards in China require a FAR of 3, roughly double that of the traditional onebay lilong. That said, additional density could be accommodated by increasing the height of each of the structures or integrating mid-rise buildings into the larger ensemble. Measured in units per acre or hectare, the residential density of the lilong could be increased by incorporating two or more units into each bay of housing. While the per-person area is significantly higher in market units than in the traditional lilong, migrants typically need less area per person. To compensate, however, units must be designed to be easily expandable.

In conclusion, adapting the lilong to fulfill market density requirements is attainable though innovative interior design layouts that facilitate adjustments both to the size of individual units and to the overall number of units.

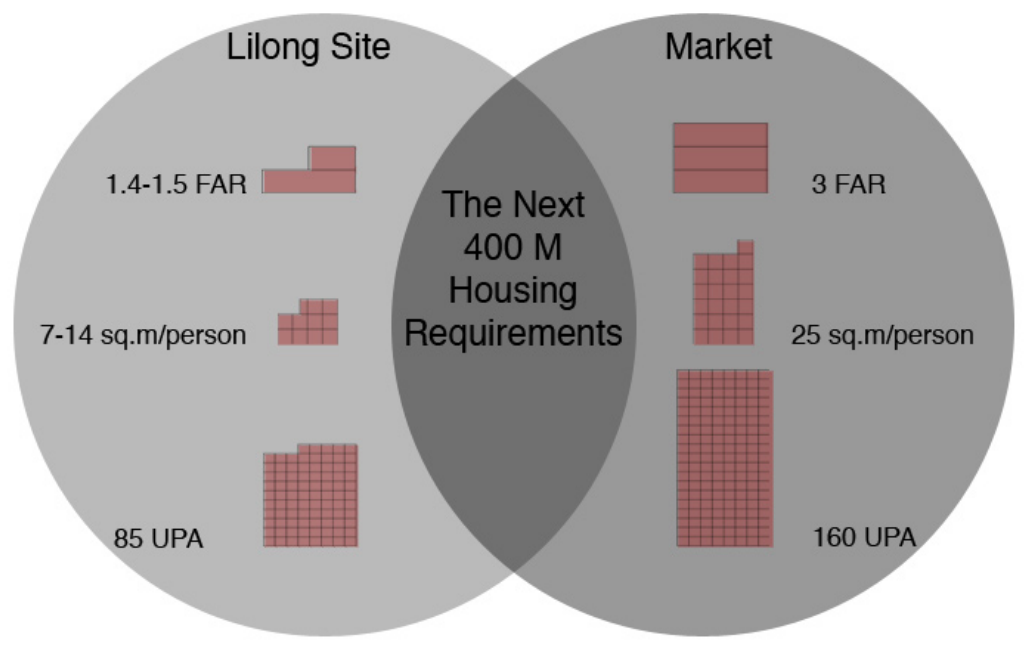

Figure 5.2 Venn diagram comparing lilong to current market standards 


\section{Flexibility}

Flexibility in how space can be used is important for migrants, whose circumstances are frequently in flux. This implies homes that can be customized and spaces whose function evolves as habits change from rural to urban. The flexibility of space associated with the lilong housing enables units to change in size, in the way they are used, and in overall density. Flexibility not only expedite the transition from rural to urban lifestyles, but it increases the chance that buildings will survive larger sifts in market demand. Figure 5.3 highlights flexible spaces in the shikumen type: high ceilings enabled the insertion of lofts, and courtyards could be used as gardens, for cooking or other forms of household production, or be enclosed to create additional interior space. Light

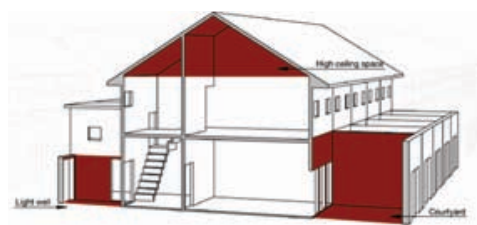
Figure 5.3 Diagram of flexible space inside the wells were frequently converted into extra rooms or used for storage.

Another approach is to design housing that can be built out incrementally. This involves putting the basic structure in place first and allow the residents to fill it in as they require. This strategy reduces costs for initial development, gives residents more control over the design of their space, and enables them to better calibrate the size of their unit to what they can afford to maintain. This

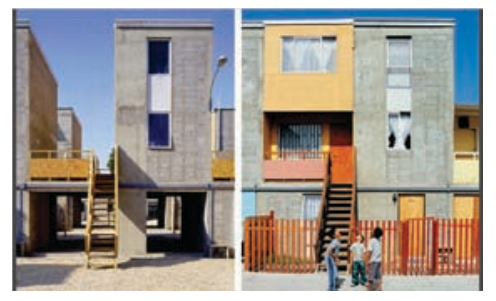

Figure 5.4 Incremental housing by Elemental Chile might be described as a structured approach to informal development.

As described in Part 6, the design portion of this project approaches flexibility by using Pods of different sizes the front and rear of the modified shikumen that can be connected or be used independently, depending on the needs of the resident. Figures 5.5 and 5.6 show different variations of pod configurations. Fig 5.5 front and rear "pods" used separately (for a total of 6 units per shikumen) 
while Fig. 5.6 shows front and rear "pods" combined to create fewer, larger apartments. This is made possible by the inclusion of a second stair that allow front and rear pods to be combined without having to use the public stair.
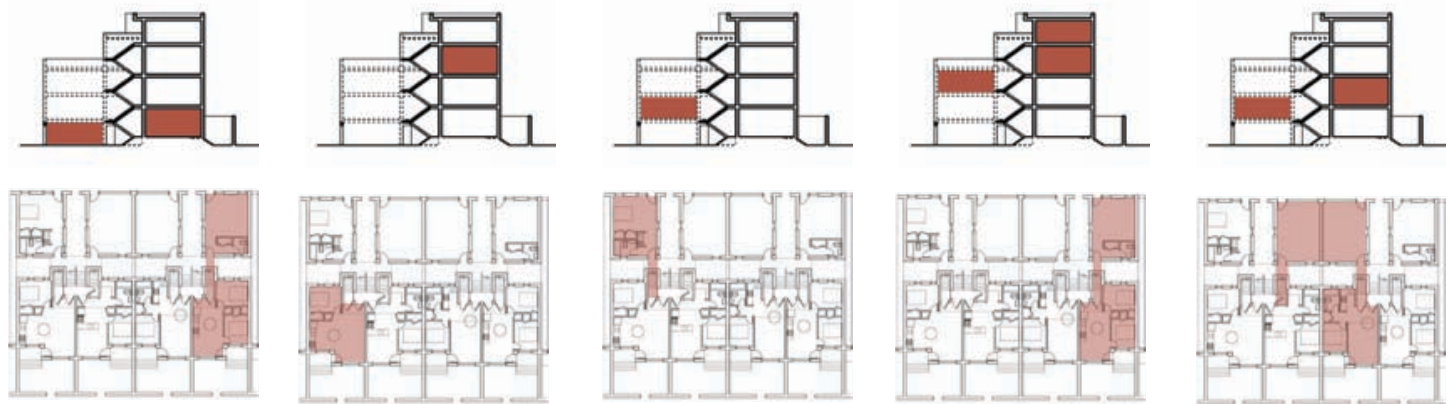

2 pods

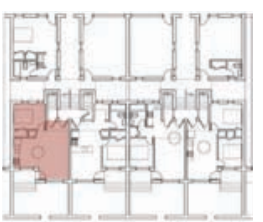

Separate

connected south pod

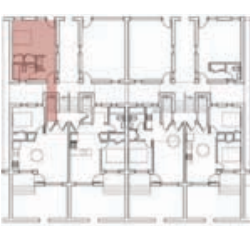

Separate north pod

Figure 5.5 Design Concept: pods can be connected in various ways creating flexible unit sizes.
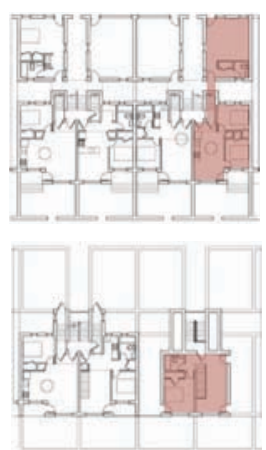

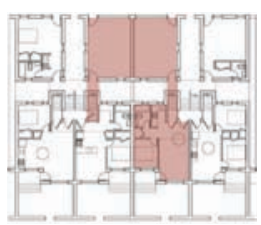

3 pods connected

2 pods connected, and loft

\section{Lighting and Ventilation}

The proposed design addresses the issues of solar orientation and natural ventilation. The incorporation of light wells and multiple windows and openings in each pod allows the interior layout to be flexible without blocking the lighting or impeding cross ventilation. When the front and rear-facing pods are connected, as shown in Figure 5.5, all units have southern orientation.

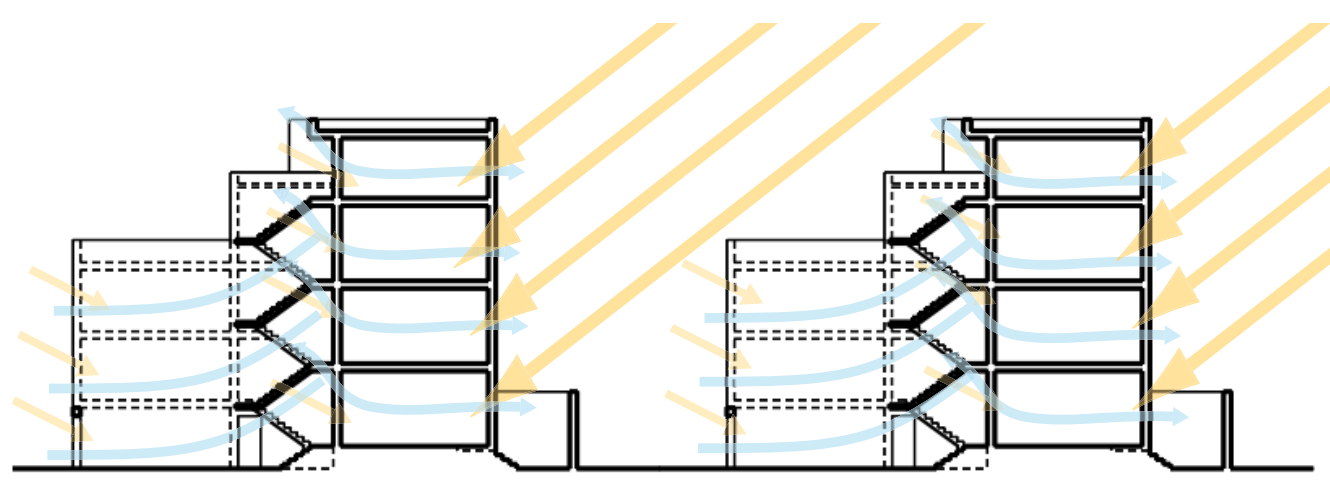

Figure 5.6 Design Concept: Diagram of lighting and ventilation 


\section{Open Space}

The dimensions of the space between residential buildings in China is frequently determined by building height, related to the distance necessary to assure each unit has direct access to sunlight. Typically the taller the buildings, the larger the spaces between them (refer back to Fig 3.5). Not surprisingly, then, "towerin-the-park" ensembles frequently include large swaths of landscaped open space. If we posit that the scale of space, in tandem with its proximity to units, affects how it can be used, it might be argued that the tight laneways of the lilongs distribute space in such a way that it is both more convenient and more useful to residents. The fact that it is scaled to individuals augments the level of comfort residents have in performing daily activities in these semi-public areas. By contrast, the large, park-like spaces of tower ensembles are typically more conducive to civil gatherings and group activities. They belong to everyone and no one.

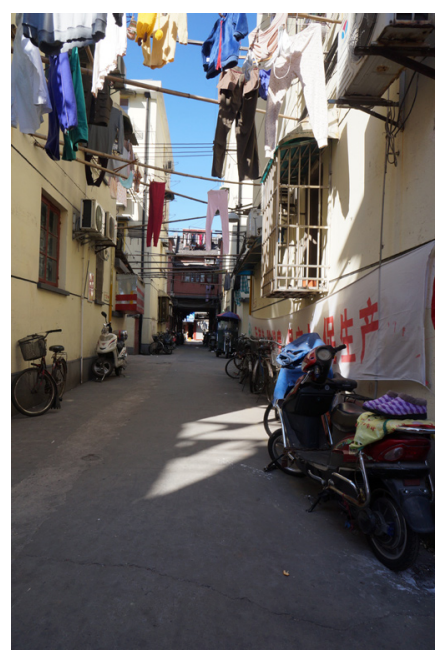

Figure 5.7 Photo inside lilong north south alleyway (zong long) in the Honkou district

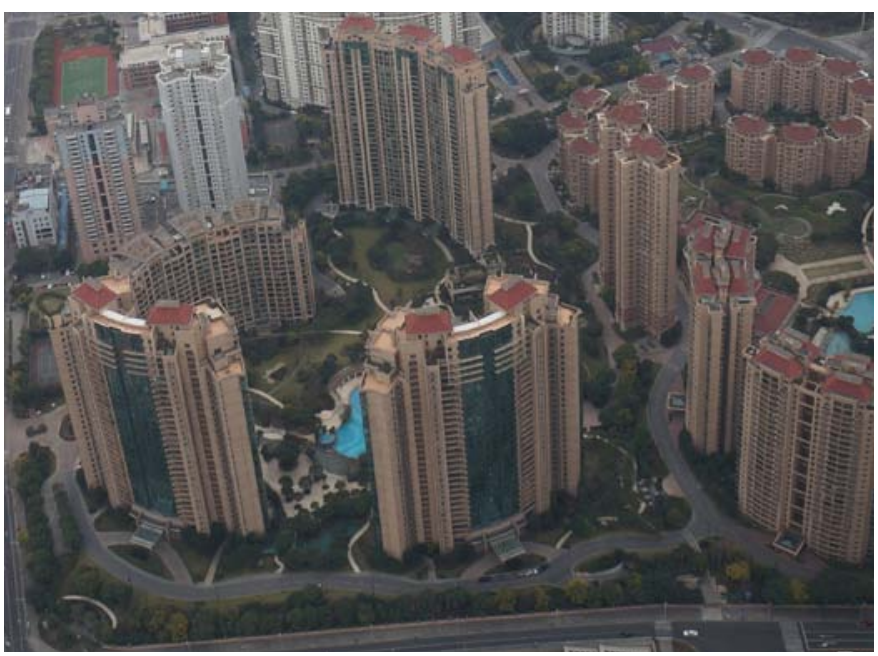

Figure 5.8 Photograph of new tower in the part developments. View is from Jin Mao Tower showing vast open spaces between buildings 
Incorporating roof top garden space accessible to all units via the common stair, increases the open space without increasing the width of laneways, keeping open spaces in scale with individual units. Food grown in rooftop gardens can to supplement the migrants when they first move into the city, but also be used as gathering spaces for social actives.

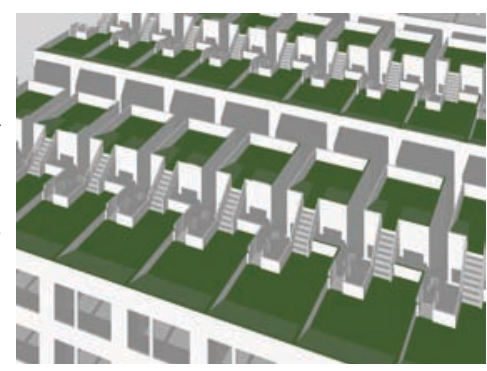

Figure 5.8 Design Concept: Open space created by roof top gardens

\section{Urban Networks and Scale}

Housing for migrants is typically located on the periphery of cities; networks that connect the urban environment together are essential as the migrants depend on developed areas to sustain themselves. Figure 5.10 is a satellite image of Shanghai and its environs. Networks of smaller cities have developed around Shanghai, creating multi-directional grids, furthering opportunities for enclaves of migrants as they can be connected to multiple secondary sources. Although

Figure 5.10 Map of Shanghai and surrounding urban

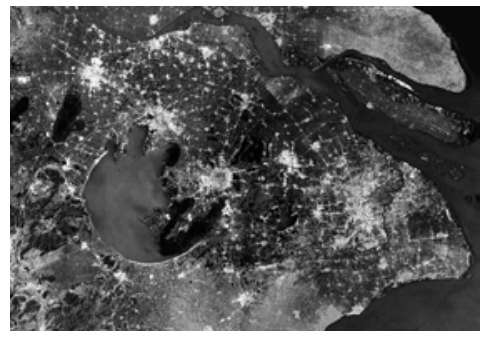
network (map edited from initially dependent other areas of the city for employment, arrival areas should Google maps screen capture) be able to transition to being self-supporting as they mature; they should be conceived as incubators for local businesses and employment opportunities.
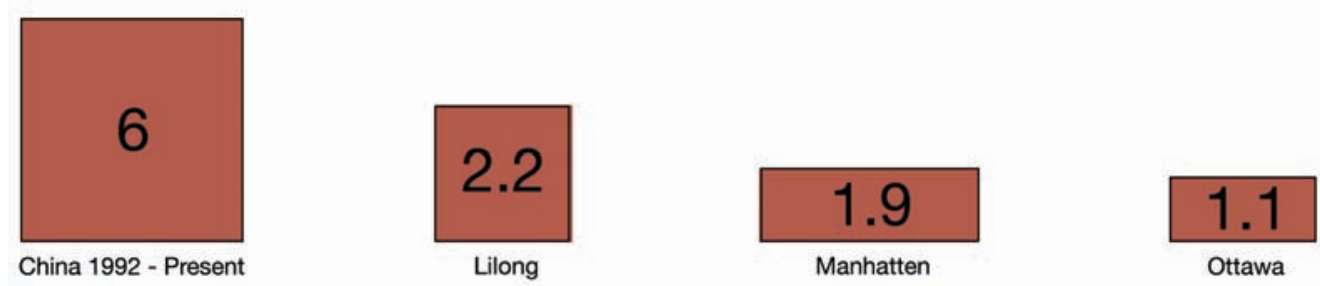

Figure 5.11 Comparing China's 6-Hectare development size to other city blocks.

Not only should homes in these developments be flexible enough to support an evolving range of household activities, but they (and the large neighborhoods into which they are aggregated) should accommodate a range of low-impact commercial activities. 
Neighborhood-scaled networks are an important means of connecting migrants to employment opportunities by through the informal transfer of information (e.g., through conversations) that may not be shared in a smaller group of friends. The typical size of a development block in China is 6 hectares. Figure 5.11 compares a 6 hectare block in China to other cities.

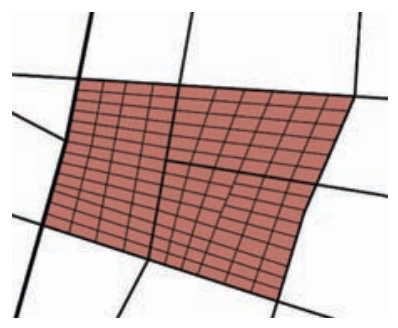

Figure 5.12 Lilong network

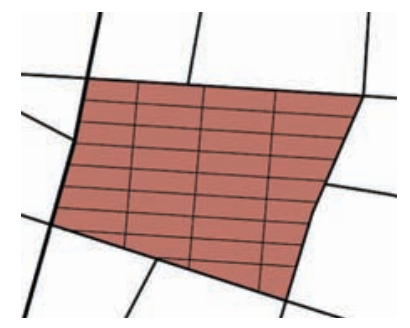

Figure 5.13 Walk-up apartment network

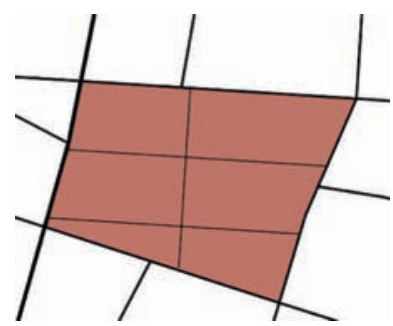

Figure 5.14 Tower in the park network

Having smaller blocks allows for more networks within the block, however this is also determined by the building size and networks within the block. Figures $5.12,5.13$, and 5.14 compare the scale of networks and spaces associated with various approaches to the development of a 6-hectare block, the typical size of a development parcel. To a significant extent, the degree of articulation of the physical network affects/reflects the sophistication of the social network. Indeed Jane Jacobs dedicated a chapter of Death and Life to "The Need for Small Blocks."

The small unit size of the lilong necessitates a finer-grained and more traditionally urban network of connections, whereas the larger networks of the mid-rise (e.g., spaces associated with danwei developments) and tower-in-the-park approaches reflect the larger scale of buildings and the comparative absence of connection between units and the ground plane. 


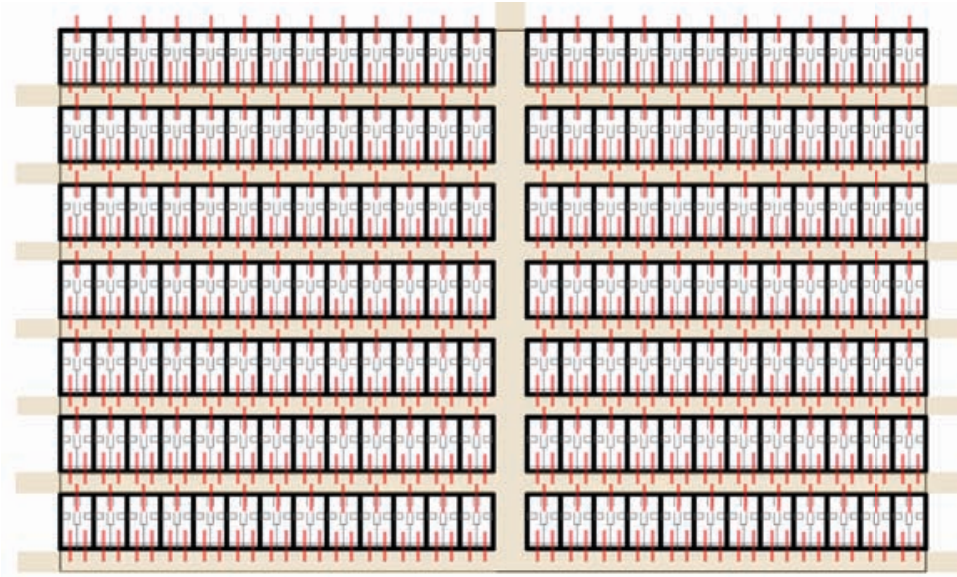

Figure 5.15 Design Concept:

Neighborhood networks

A key aspect of the lilong network are the smaller east-west alleys onto which houses front and which connect to the larger north south axis. The design portion of this project incorporates the different sizes of networks into the neighborhood. The neighbourhood drawing in Fig 5.15 shows the narrow eastwest alleys that connect to the house. While wide enough to accommodate cars, these laneways (or zhi long) are primarily pedestrian in nature. The larger north-south networks (or zong long) can accommodate more cars, as well as space for pedestrians to gather, however the streets are still much smaller than the multi-lane traffic connecting neighborhoods to the surrounding urban city.

The red lines in Fig 5.15 show the paths and points of connections between individual units and the neighbourhood network. Although many modernist high-rises have attempted to create so-called streets in the sky, these spaces have been generally been unsuccessful.

Among the goals for the design portion of the thesis, then, is to improve the number and quality of the connections between individual units and the 


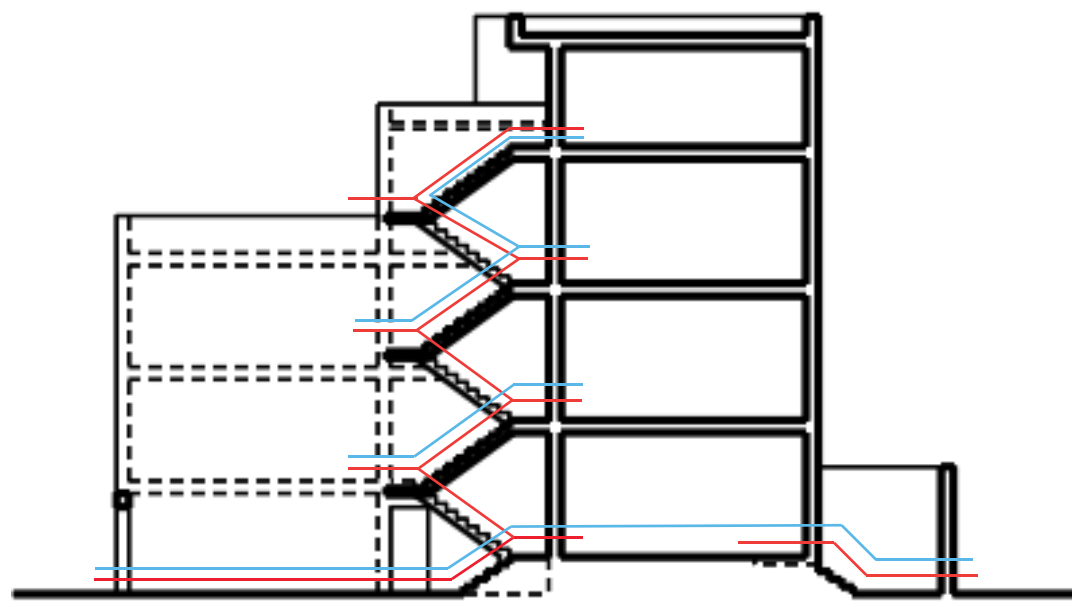

Figure 5.16 Design Concept: Interior building networks, private paths are shown in blue and public paths are shown in red

neighbourhood. Part 6 includes proposals for a modified version of the shikumen, the housing type associated with the lilong. The multiple connections are a part of a micro network that connects the building directly to the urban fabric. The stairs shown in Fiq 5.16 enable the modified shikumen to be subdivided in a variety of ways but brings the micro network, that connects the resident to the urban environment, directly into the space. More detailed drawings of the modified shikumen are included in Part 6 based on the terms of reference and the design concepts developed in this chapter.

Another important aspect of the lilong housing is that blocks were frequently enframed by a continuous, two- or three-story 'perimeter block' building. Walled off from the city and largely hidden from view, dense lilongs in the center of urban blocks largely functioned like as separate neighborhoods within the city. The perimeter buildings and commercial functions connected the lilong housing neighborhood, to the larger urban fabric. Surrounding perimeter buildings allow 
for the interior block of housing to be quieter than the busy streets perimeter streets but easily accessible, by pedestrian or vehicle access.

The design approach explores alternatives to the one-size-fits-all approach by a way of better accommodating rural-to-urban migrants, if and how the lilong, a "traditional" form of migrant housing in China can be adapted, and working from the scale of the unit to the scale of the neighborhood.

\section{The Unit}

The design principle of the unit is flexibility, creating spaces that can easily be subdivided so that portions of all the units can be rented out. This is achieved by multiple points of entry, redundant circulation, adequate provision of plumbing hook ups for bathrooms, and multiple windows for ventilation. Each standard unit of two pods receives sunlight as per residential regulations of 2 hours of continuous sunlight between 10:00 am and 2:pm on Dec.21. Each unit has direct access to exterior space though unit balconies, and a common roof top garden. The unit sq.ft per person meets the standard market requirement, creating units that can be subdivided for lower costs, or sold at market standards. Accommodation in the main floor pods and for non-residential uses encourages informal economies and entrepreneurship, that was vital in the lilong communities. Main floor pods can be used for parking, a double shikumen is designed to provide up to three vehicle spaces. The flexibility of space and use of space is designed to create a unit that works differently but equally as well for residents of different economic means. The housing design incorporates market standards to make the transition to middle-class market housing. 


\section{The Neighborhood}

The design principle of the neighborhood row-house layout is keep in respect to staying true to the shikumen model and capitalizing on the cultural resonance. However, important changes are required to make the block porous and allowing vehicle access without compromising sense of identity or security of community inside of the block. Multiple spatial networks are incorporated in the connection between the unit, neighborhood, and urban fabric. A hierarchal network of public, semi-public, semi-private, and private spaces is created by different scales and proximity to the units; all spaces well-defined in spacial boundaries. These factors determine how the spaces are used and by whom. The small scale of a shikumen unit allows for regularity and flexibility in the urban fabric. A key design factor is creating blocks that are identifiable as urban fabric that connects and works with the adjacent blocks to create a larger "urban" whole. The neighborhood block is required to privilege pedestrian movement while accommodating movement and parking of vehicles; important for residents, visitors, and emergency vehicles. Design consideration of the neighborhood spaces and networks is important to orchestrate and encourage social interaction between residents. Larger scale neighborhood considerations adheres to current regulations regarding solar orientation (supporting the unit design to ensure main rooms receive 2hours of daylight in December), and accommodating a mix of uses and a variety of building types. The goal of rethinking the lilong model is to provide a more sustainable option to the towerin-the-park urbanism. 


\section{Design Proposal}

The design proposal works from a standard one-bay and two bay lilong, adjusting room sizes and building widths to accommodate vehicle storage. Shikumen Variation 1 adds complex stairs that allow for each pod to have separate entrances, or privately connect multiple pods. ${ }^{1}$ This design is then furthered by connecting the units as row houses, this allows for common stairs as well as the possibility of connecting pods horizontally. Also taken into account is the sun requirement for residential housing; minimum two hours of direct day lighting during the winter solstice. The residential block was than combined into the neighbored, proving the flexibility of the lilong scale in the urban fabric.

$\overline{1}$ Rethinking the split house by Neri \& Hu Design and Research Office

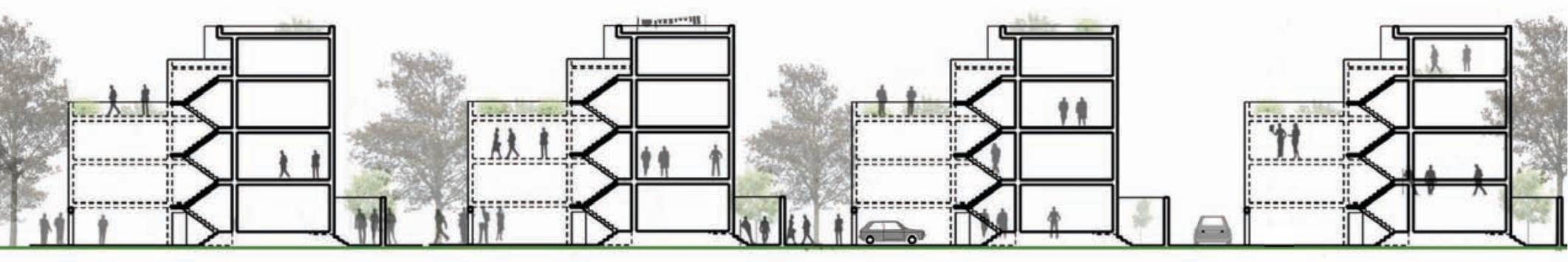




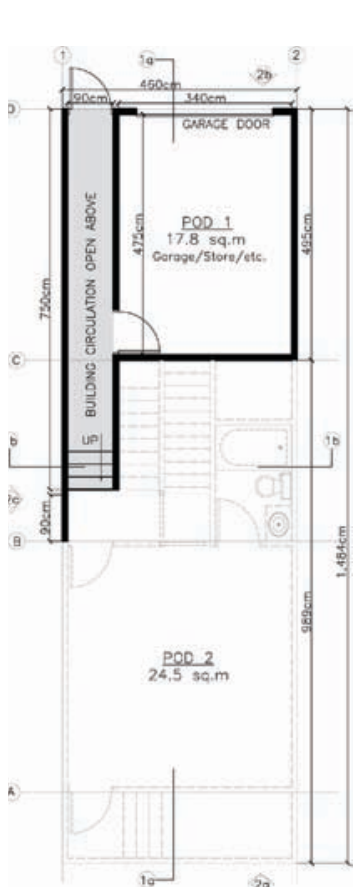

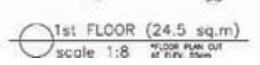
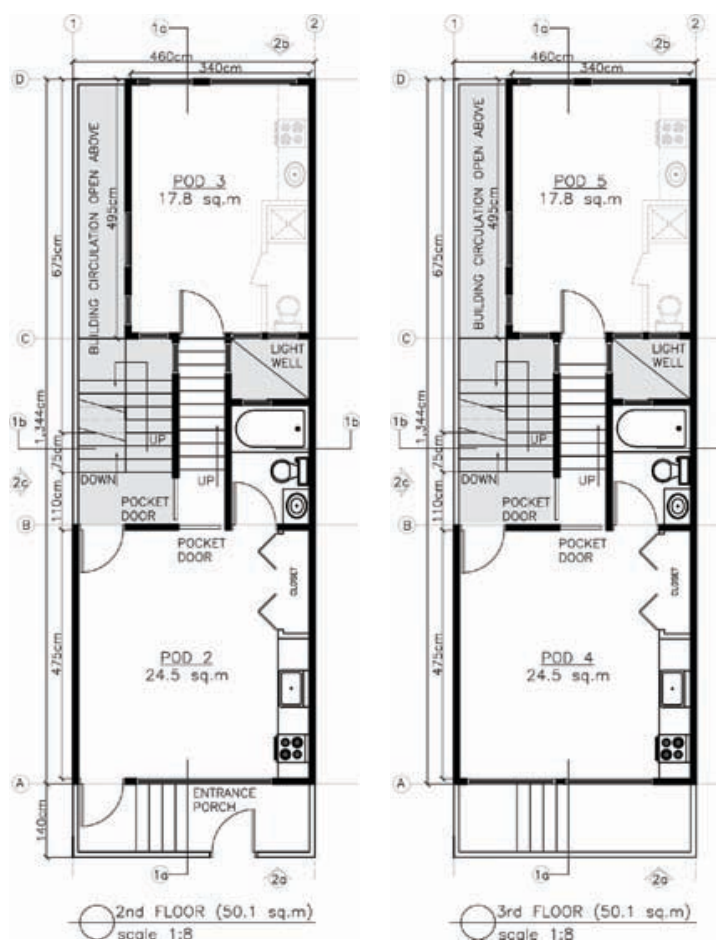
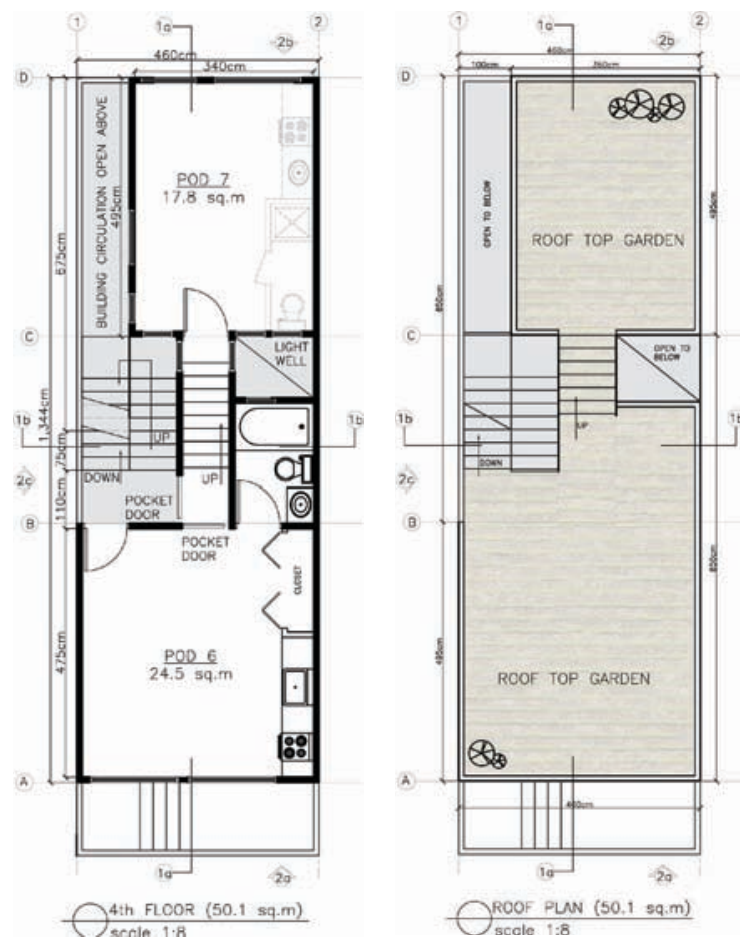

Shikumen Variation 1

Overall Area: 95.8 sq.m

Total Open Space: 86.2

Courtyards: 7.4 sq.m

Circulation: 10.7 sq.m

Roof top Garden: 40.5 sq.m

Laneway: 27.6 sq.m

Percentage open to Owners: $89 \%$

Percentage open to Public: 29\%

Total Built area: 163 sq.m

Area Per Floor: 48.4 sq.m

Pod 1: 17.8 sq.m

FAR: 1.7

UPA:

3.5 units per Shikumen: 87 UPA

7 units per Shikumen: 175 UPA

Laneway Size

East/West Laneway 6m (20')

North/South Laneway 12m (40') 

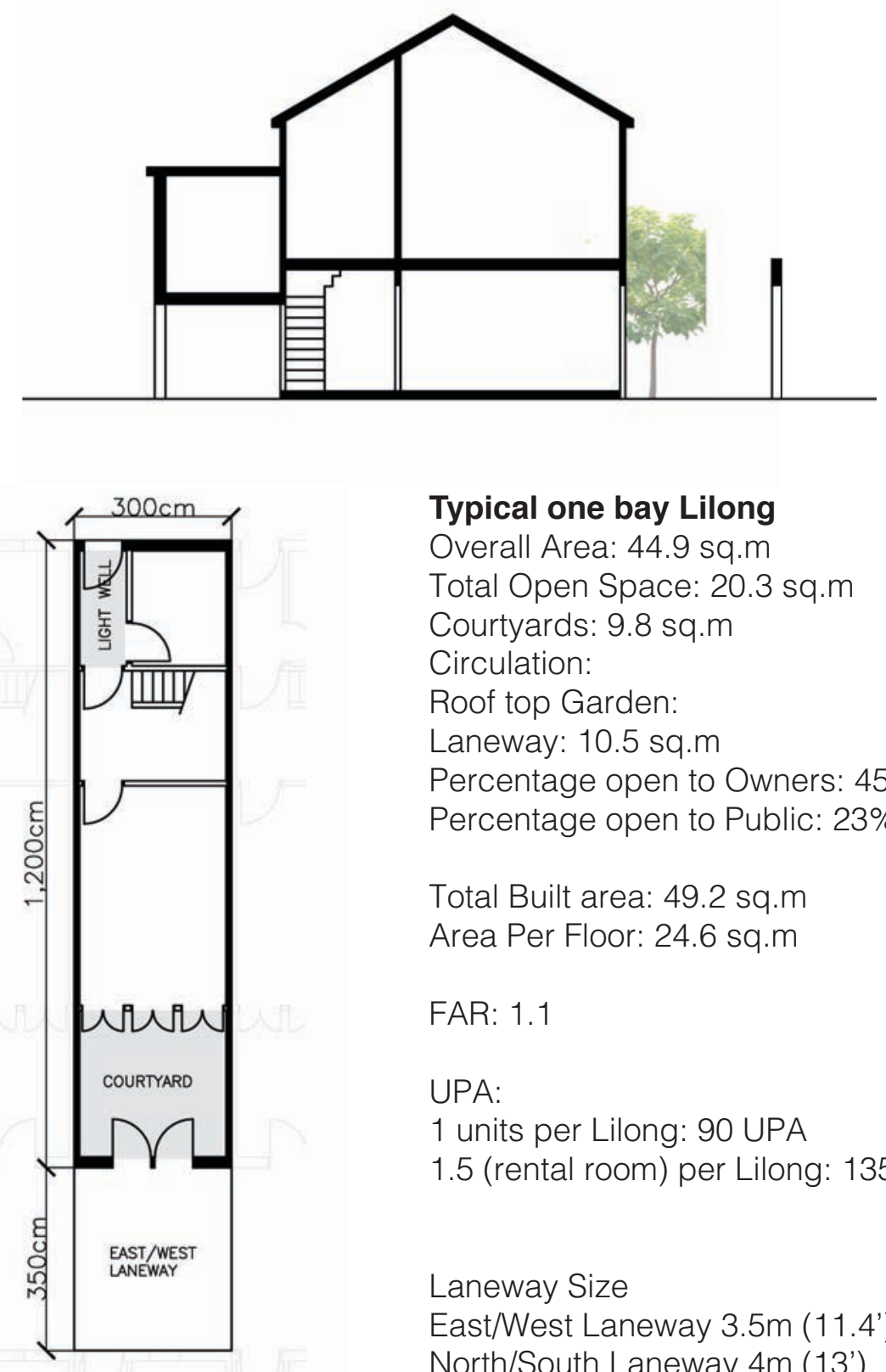

Typical one bay Lilong

Overall Area: 44.9 sq.m

Total Open Space: 20.3 sq.m

Courtyards: 9.8 sq.m

Circulation:

Roof top Garden:

Laneway: 10.5 sq.m

Percentage open to Owners: $45 \%$

Percentage open to Public: 23\%

Total Built area: 49.2 sq.m

Area Per Floor: 24.6 sq.m

FAR: 1.1

UPA:

1 units per Lilong: 90 UPA

1.5 (rental room) per Lilong: 135 UPA

Laneway Size

East/West Laneway 3.5m (11.4')

North/South Laneway 4m (13') 


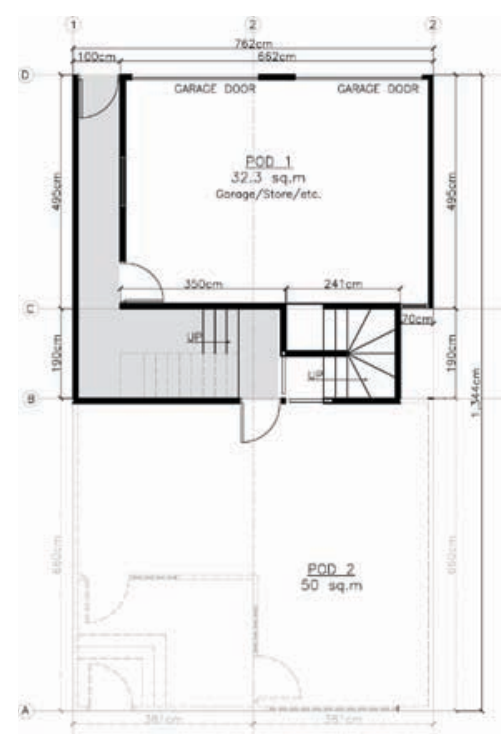

Otst FLOOR $(1.240 \mathrm{sacm})$

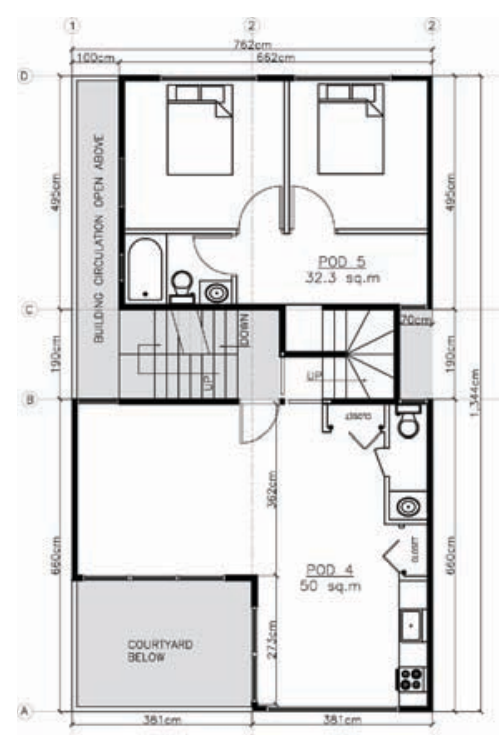

Srd n.oor (1.240 sa.tr)

- Possibie layout - 2 pod unit

layout
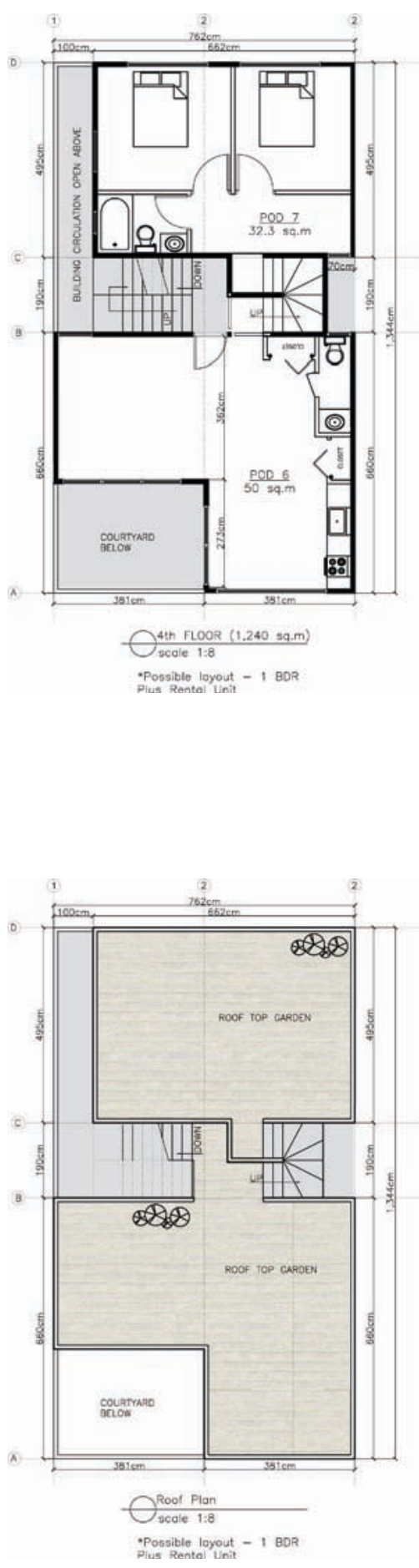

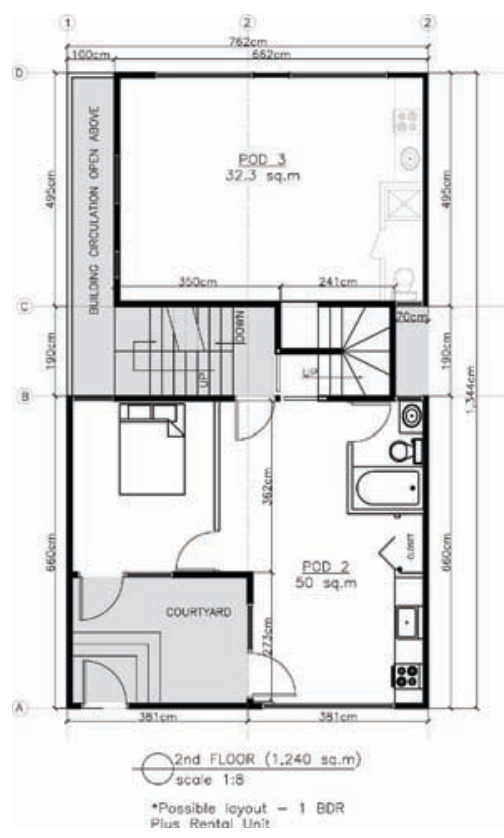

Shikumen Variation 1

Overall Area: 95.8 sq.m

Total Open Space: 86.2

Courtyards: 7.4 sq.m

Circulation: 10.7 sq.m

Roof top Garden: 40.5 sq.m

Laneway: 27.6 sq.m

Percentage open to Owners: $89 \%$

Percentage open to Public: $29 \%$

Total Built area: 163 sq.m

Area Per Floor: 48.4 sq.m

Pod 1: 17.8 sq.m

FAR: 1.7

UPA:

3.5 units per Shikumen: 87 UPA

7 units per Shikumen: 175 UPA

Laneway Size

East/West Laneway 6m (20')

North/South Laneway 12m (40') 


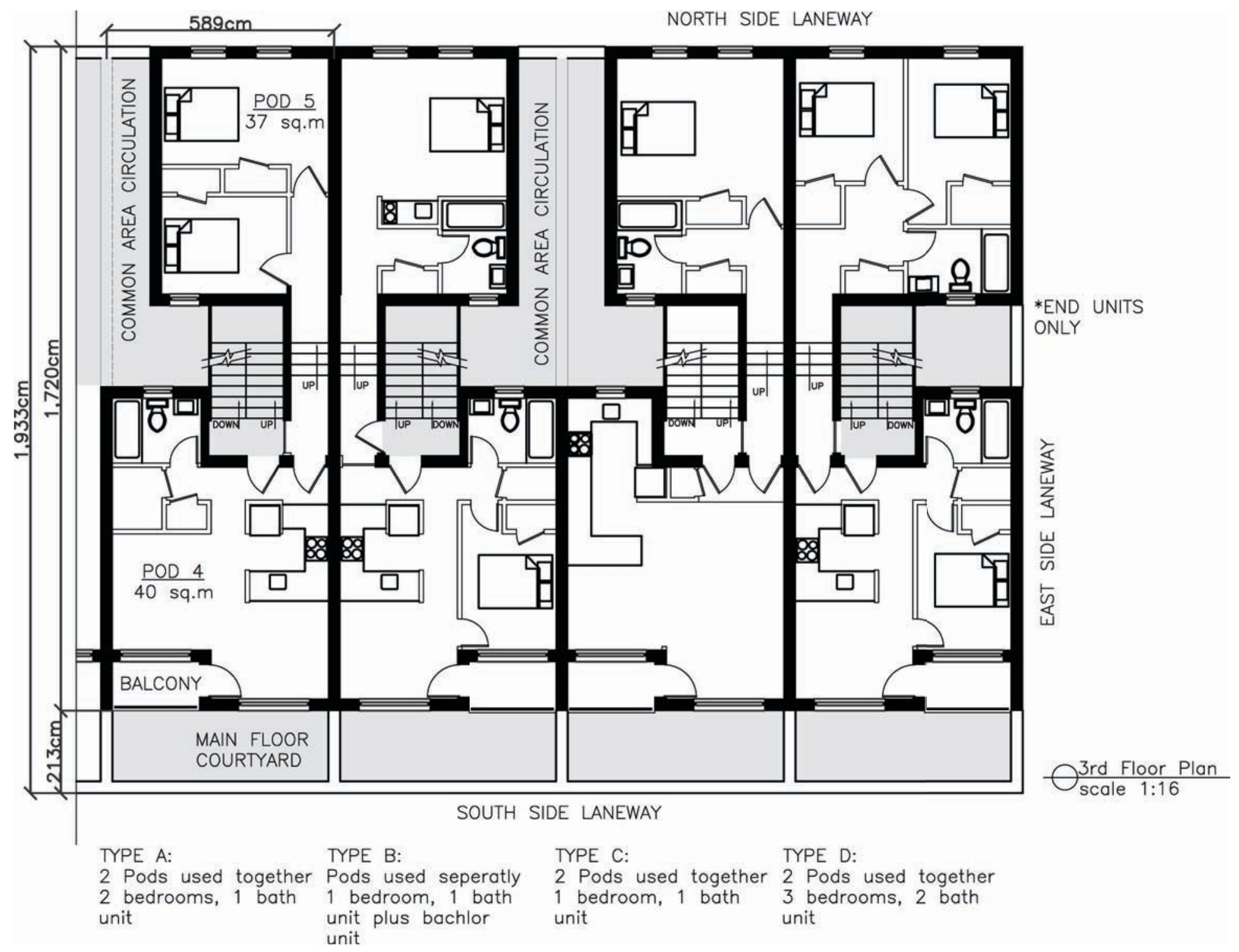

Unit Numbers

Total Floor Plate: 77 sq.m

(not including common stairs, balconies

or courtyard)

Front Pod: 40 sq.m

Rear Pod: 37 sq.m

Area Per Person: 25.5 - 18.5 sq.m 


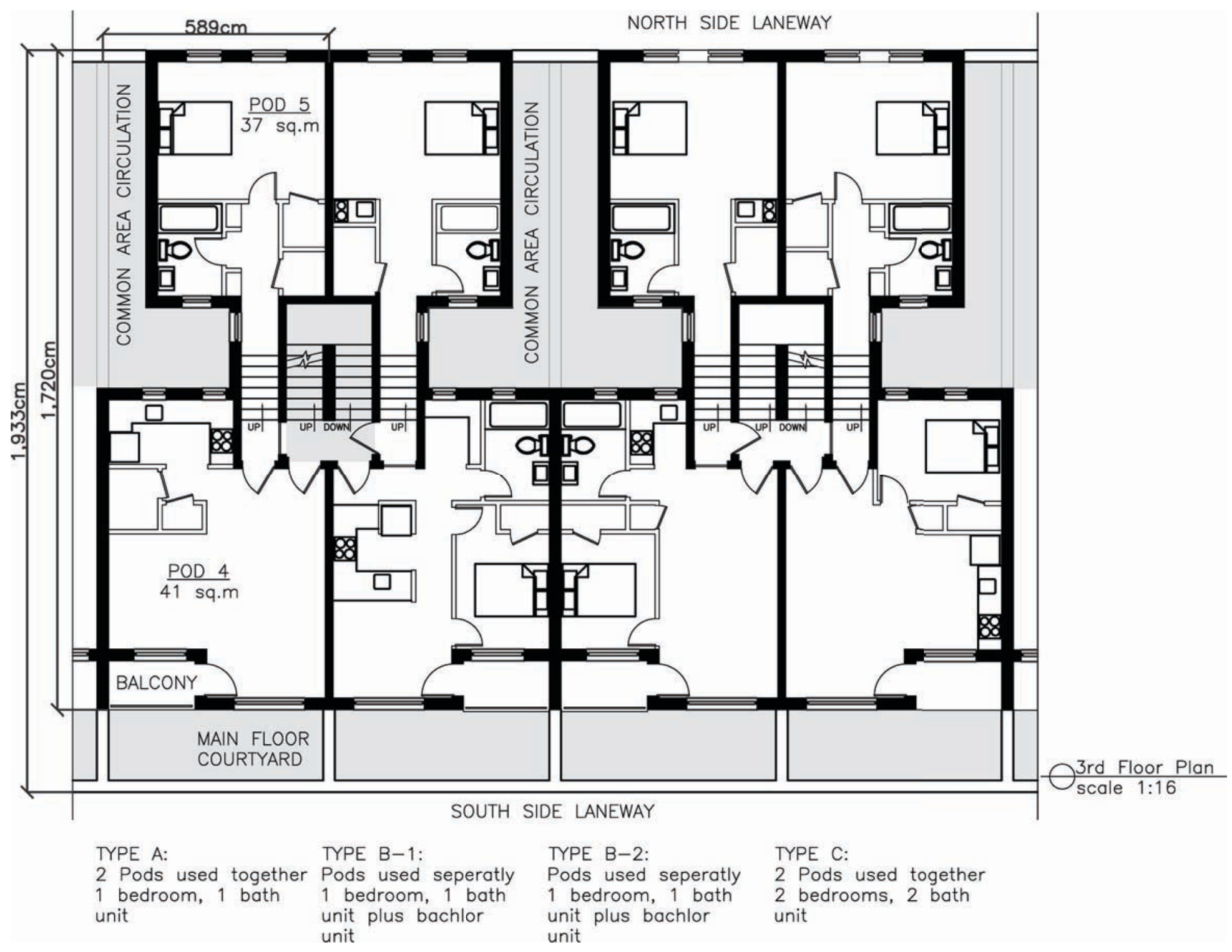

Unit Numbers

Total Floor Plate: 78 sq.m

(not including common stairs, balconies

or courtyard)

Front Pod: 41 sq.m

Rear Pod: 37 sq.m

Area Per Person: 26- 18.5 sq.m 


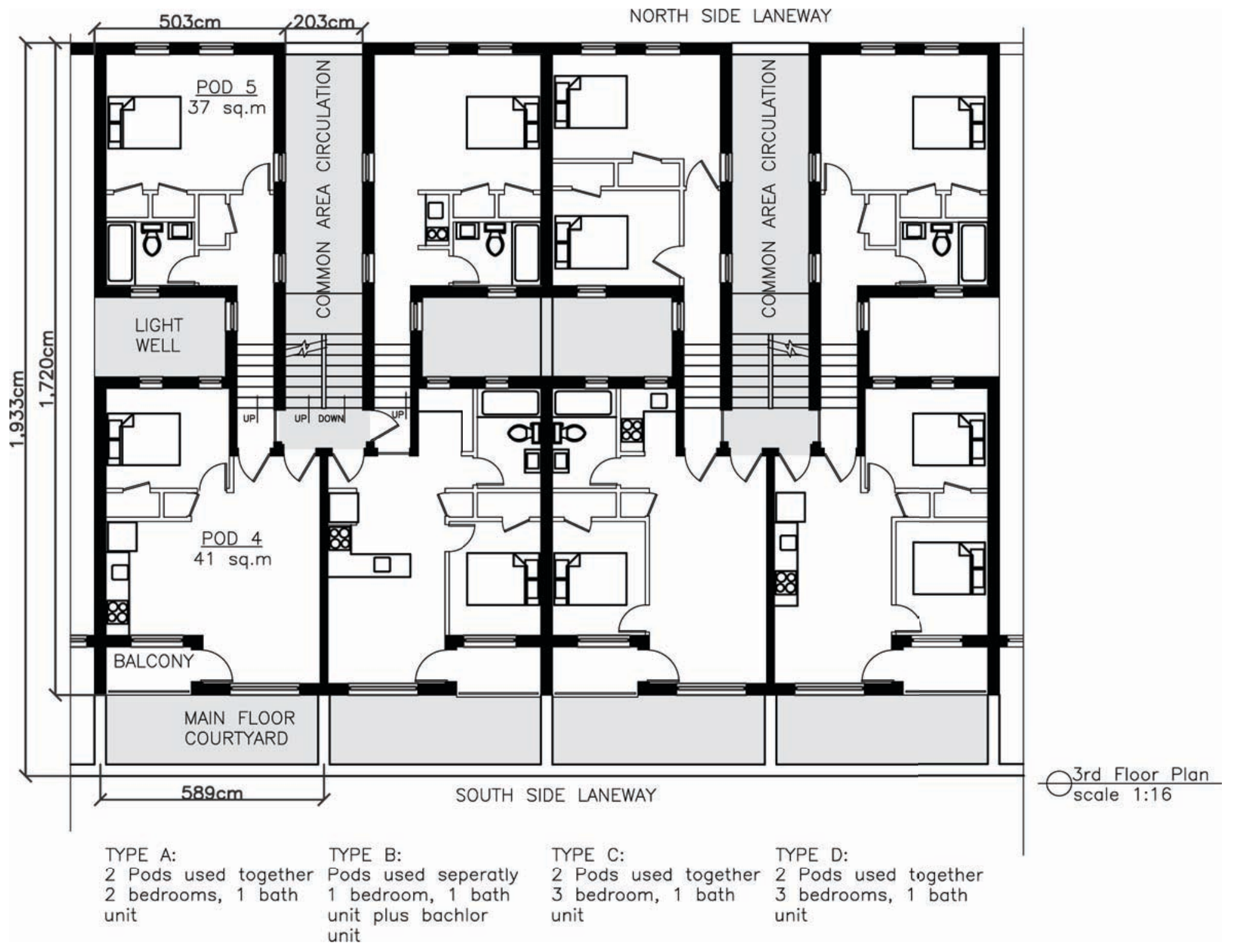

\section{Unit Numbers}

Total Floor Plate: 78 sq.m

(not including common stairs, balconies

or courtyard)

Front Pod: 41 sq.m

Rear Pod: 37 sq.m

Area Per Person: 26- 18.5 sq.m 


\section{Variation 3: June 21}

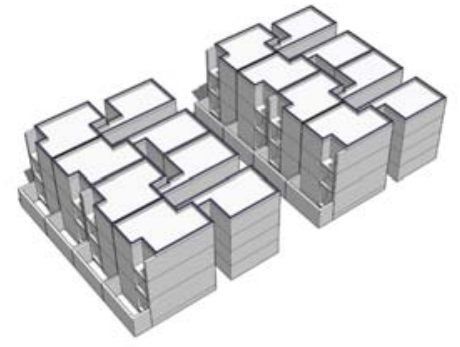

10:00am

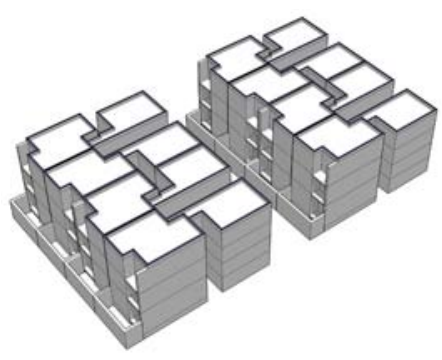

11:00am

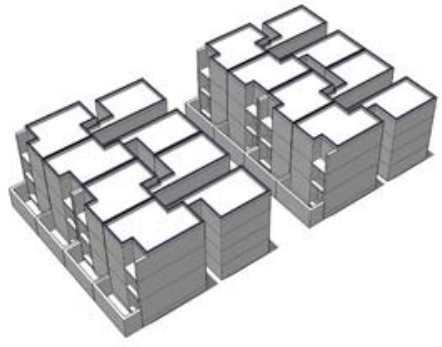

12:00pm

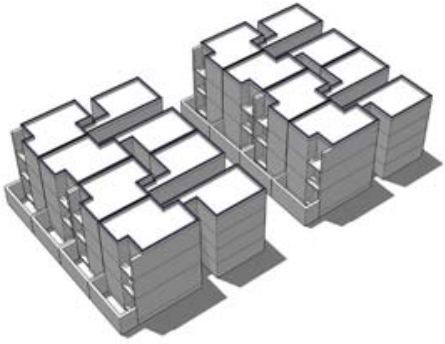

1:00pm

\section{Variation 3: December 21}

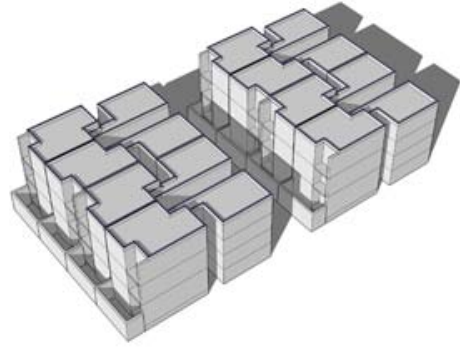

10:00am

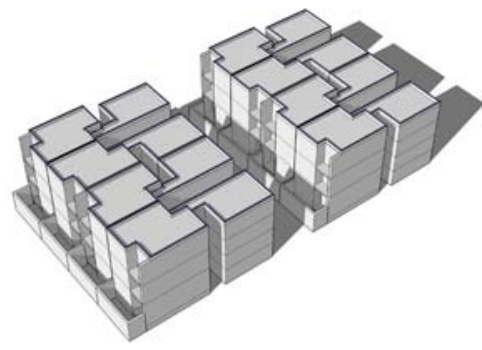

11:00am

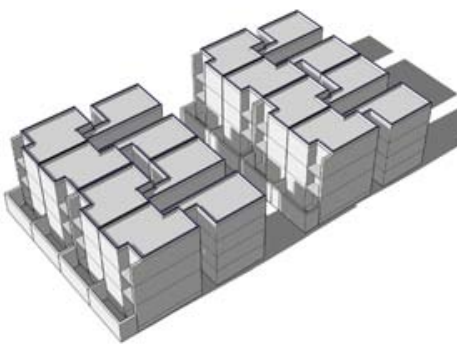

12:00pm

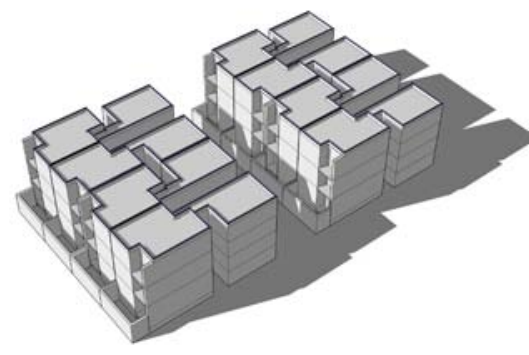

1:00pm

Variation 4: June 21 (change of Massing and laneway depth)

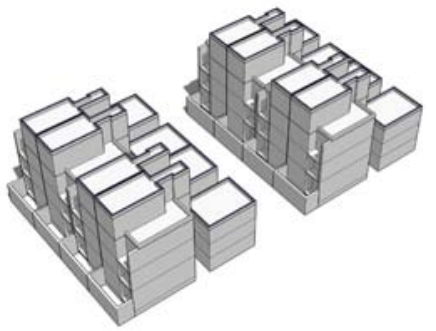

10:00am

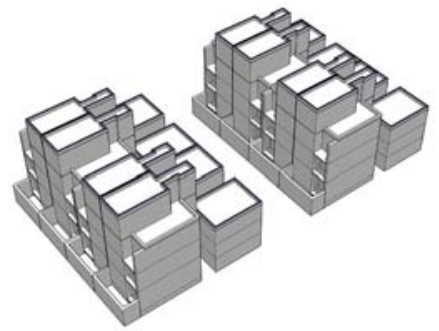

11:00am

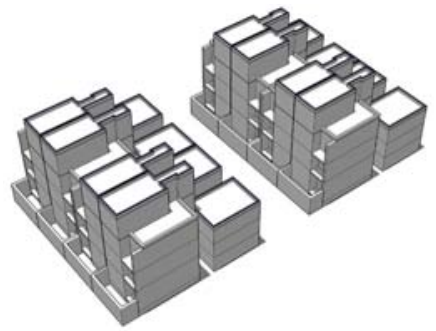

12:00pm

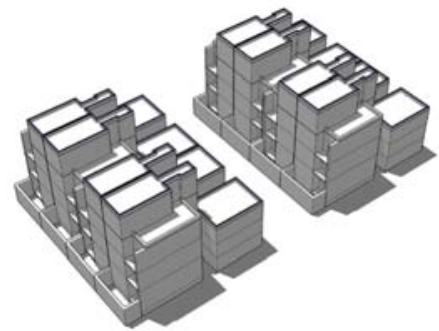

1:00pm

\section{Variation 4: December 21}

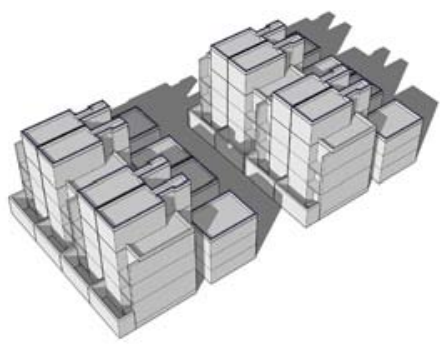

10:00am

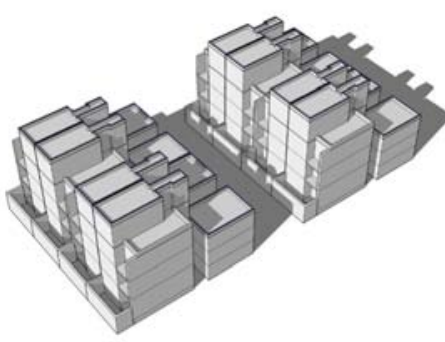

11:00am

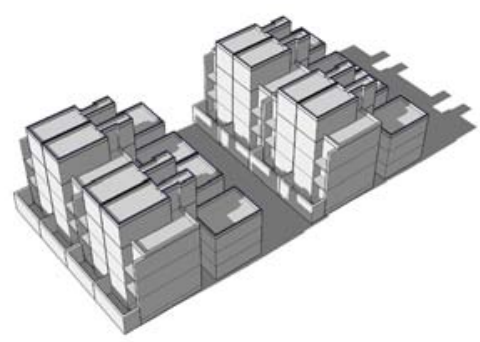

12:00pm

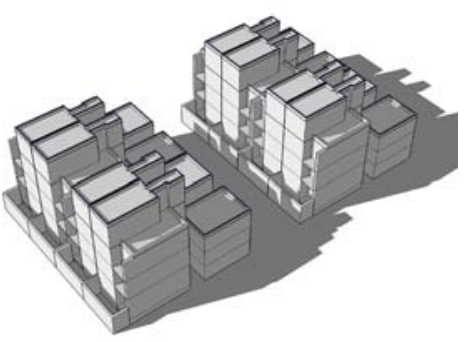

1:00pm 83 


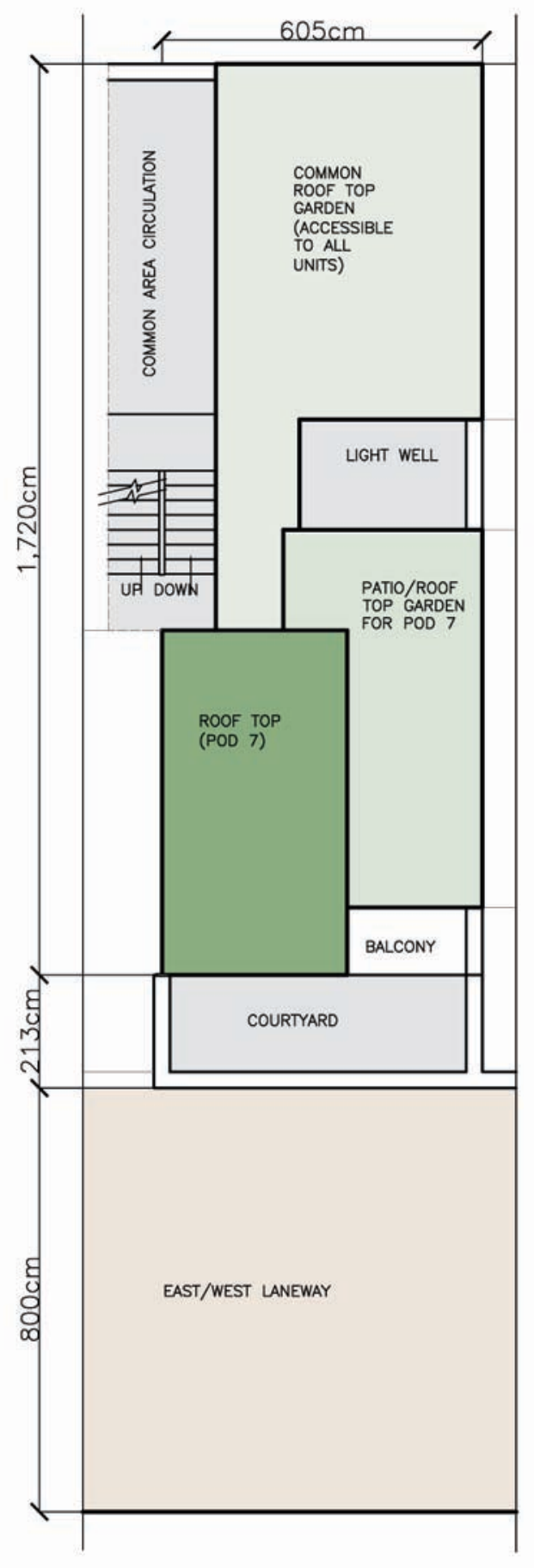

\section{Shikumen Variation 4}

Overall Area: 161 sq.m

Total open space: 113.8

Courtyards: 16.8 sq.m

Circulation: 10.5 sq.m

Common roof top garden: 39.4 sq.m Laneway: 47.1 sq.m

Percentage open to unit owners: $70 \%$

Percentage open to public: $30 \%$

Total built area: 276.2 sq.m

Area per floor: 84.5 sq.m

Pod 7(loft): 22.7 sq.m

FAR: 1.8

UPA:

3.5 units per shikumen: 87 UPA

7 units per shikumen: 175 UPA

Laneway Size

East/West laneway 6m (20')

North/South laneway 12m (40')

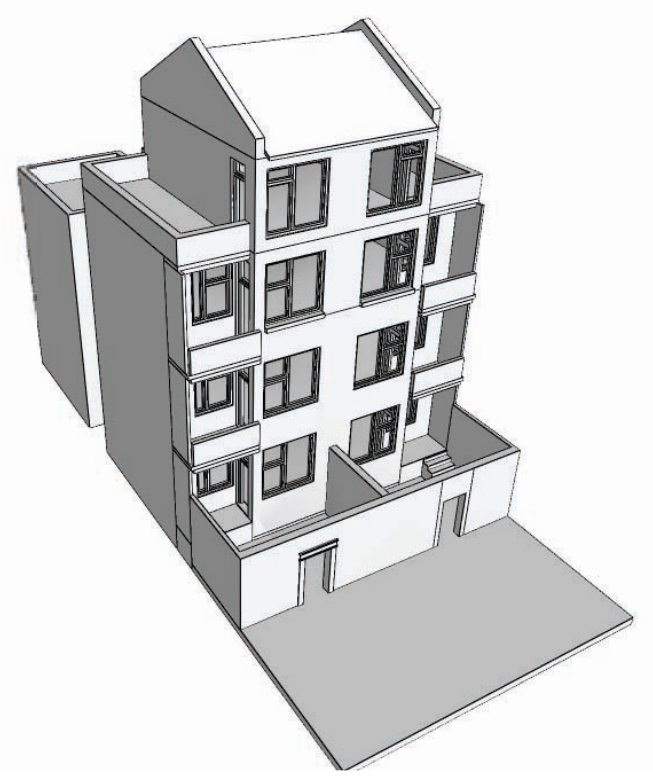


Neighborhood Iteration 1

Targets

Target FAR: 3

Target open space $50 \%$ or higher

\section{Potential Units}

25 double shikumen units $\times 7$ rows: 175

13 pods per double unit: 2275

\section{Estimated Residential Units}

Rear pod to be used as garage: 350

Front pod on South edge to be used as commercia Net unit number: 1875

\section{UPA}

Potential UPA: 154

Net UPA: 127

Total Built Area: 96,670 sq.m

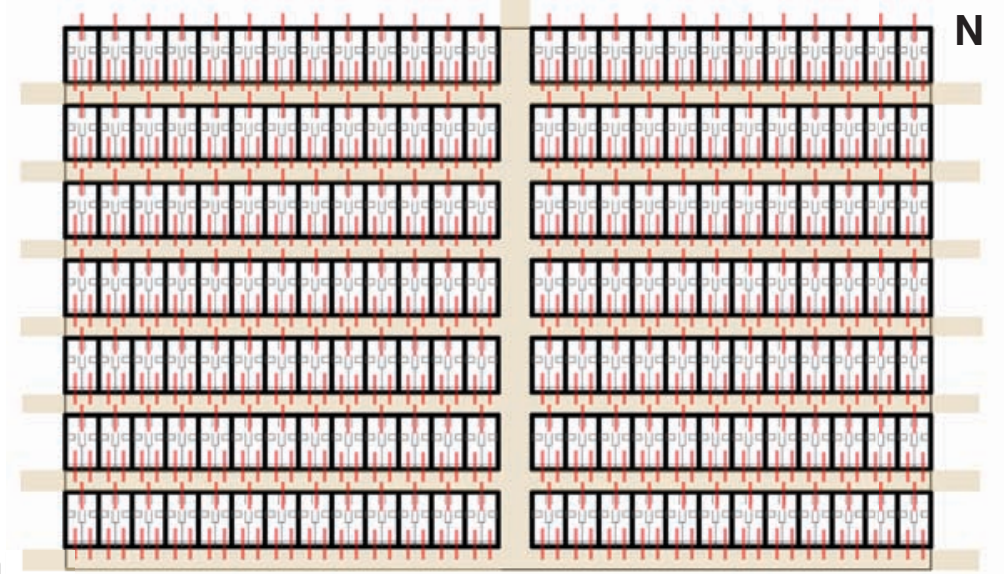

Site

Area: 6 Hectares (14.8 acres)

Dimensions: 306m x 191m (1032' x 626')

\section{Laneway Size}

East/West laneway 6m (20')

North/South laneway 12m (40')

FAR 1.6

Total Open Space:

Public: (laneways) 10,050 sq.m (18\%)

Owners: 42,010 sq.m (72\%)

Neighborhood Block 85 


\section{Targets}

Target FAR: 3

Target open apace 50\% or higher

\section{Changes from Iteration 1}

Remove residential units from North row (-225 Pods) Add 1 storey commercial and 5 storeys residential (4 pods per floor) (500)

Remove 3 shikumen buildings in row 2-5 on each side $(-195)$

Add 1 storey commercial on West and East sides

Add mid rise 4 storey residential on West and East sides (10 Pods $\times 14$ buildings $=140)$

\section{Estimated Residential Units}

Units removed 420

Units added 640

Net unit number: 2,095

UPA 141

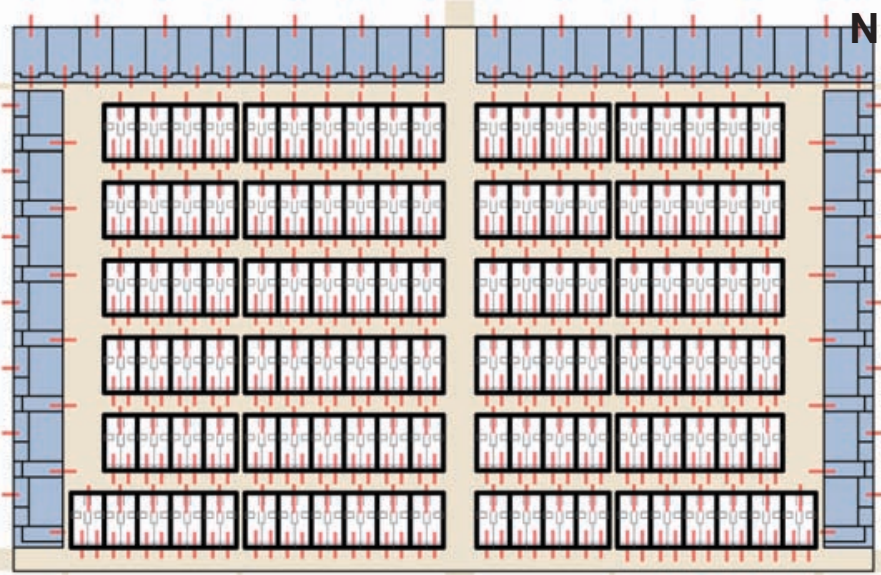

Site

Area: 6 Hectares (14.8 acres)

Dimensions: 306m x 191m (1032' x 626')

\section{Laneway Size}

East/West laneway 6m (20')

North/South laneway 12m (40')

Total Built Area: 127,158 sq.m

Commercial area 11,474 sq.m

Shikumen 85,008 sq.m

Mid-rise residential 30,676 sq.m

FAR 2.17

\section{Total Open Space:}

Public: (laneways) 16,476 sq.m (28\%)

Owners: 11,245 sq.m (20\%)

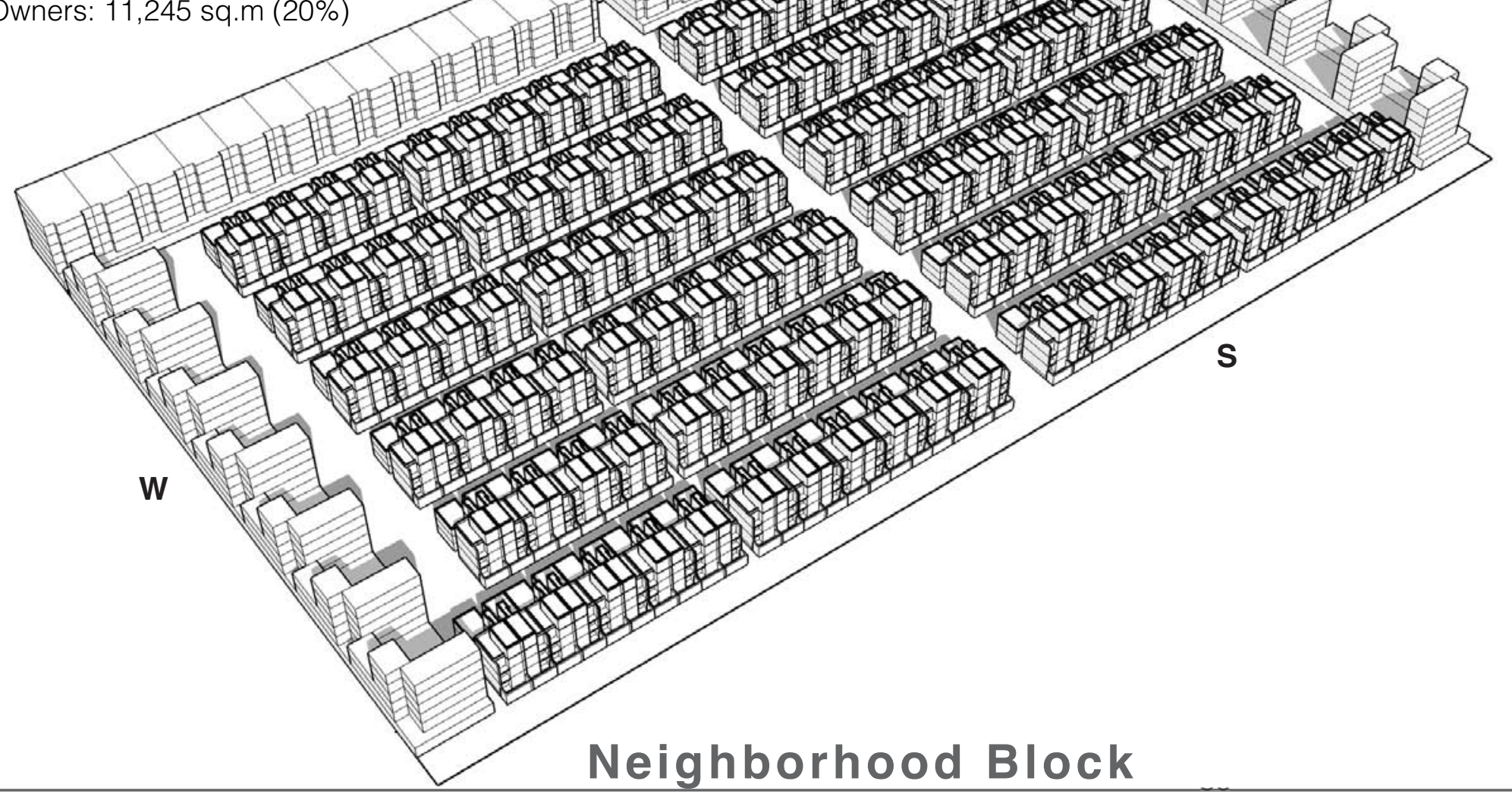


Target FAR: 3

Target open apace 50\% or higher

\section{Changes from Iteration 2}

Remove 6 shikumen buildings (-78 units)

Remove 4 mid-rise buildings (-40 units)

Add 2 - 20 storey (4 units per floor x 19 storeys) 152

Estimated Residential Units

Units removed 118

Units added 152

Net unit number: 2,129

UPA 144

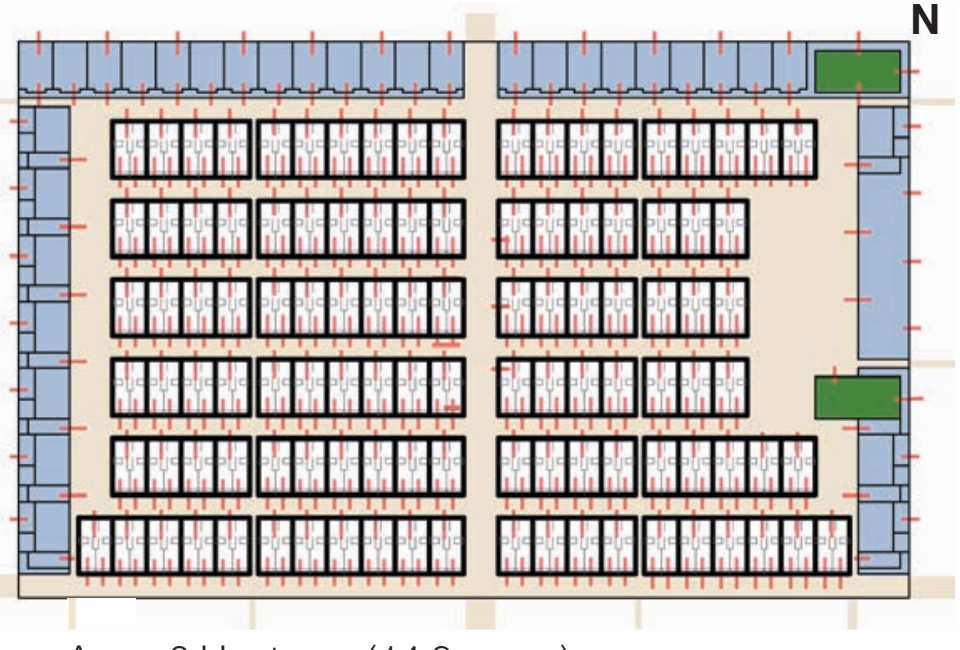

Total Built Area: 133,453 sq.m

Commercial area 11,474 sq.m

Shikumen 83,994 sq.m

Mid-rise residential 21,911 sq.m

High rise 16,074 sq.m

FAR 2.3

Area: 6 Hectares (14.8 acres)

Dimensions: 306m x 191m (1032' x 626')

\section{Laneway Size}

East/West laneway 6m (20')

North/South laneway 12m (40')

\section{Total Open Space:}

Public: (laneways) 17,841 sq.m (30.5\%)

Owners: 11,877 sq.m (20.3\%)

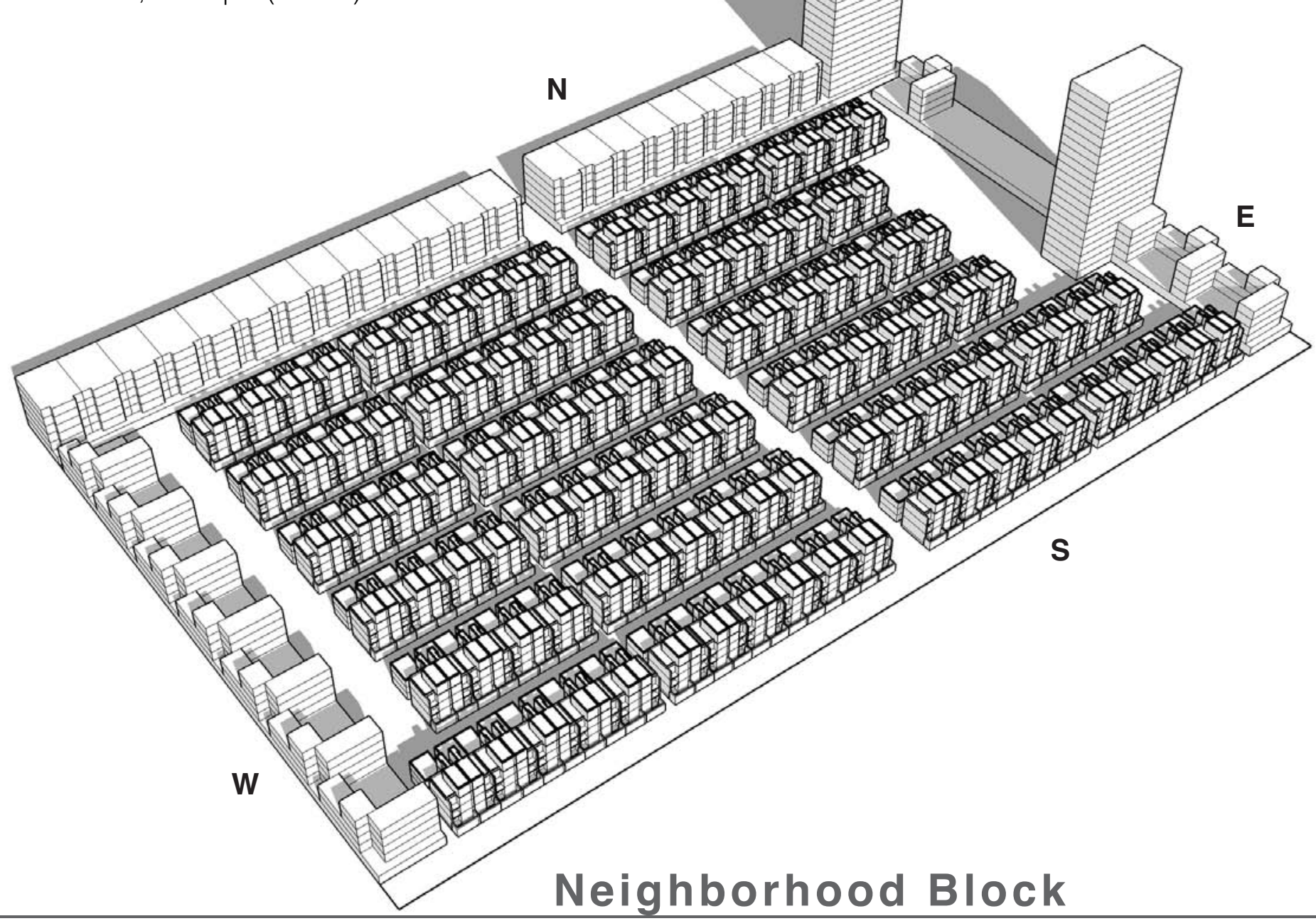



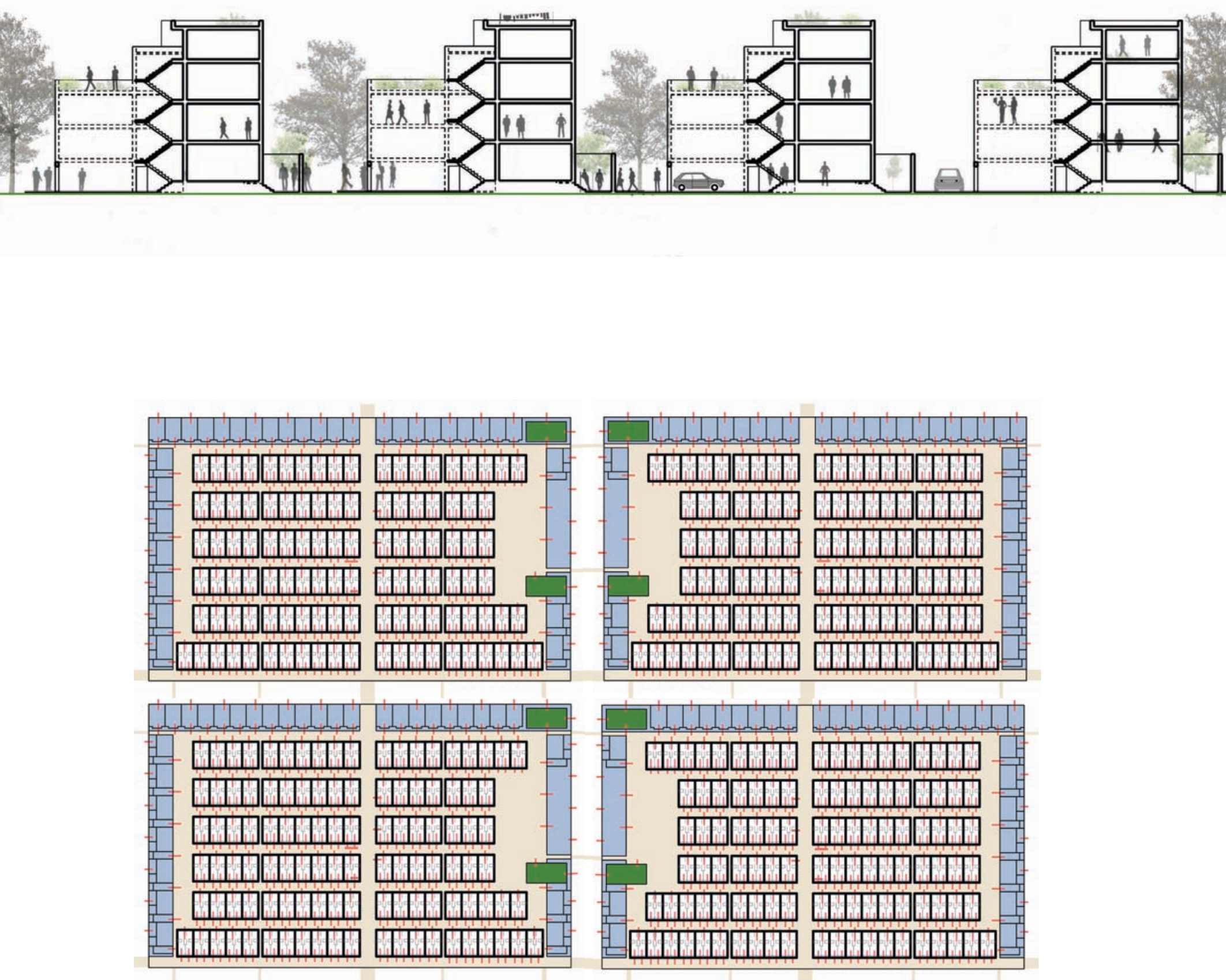

Neighborhood street 88 


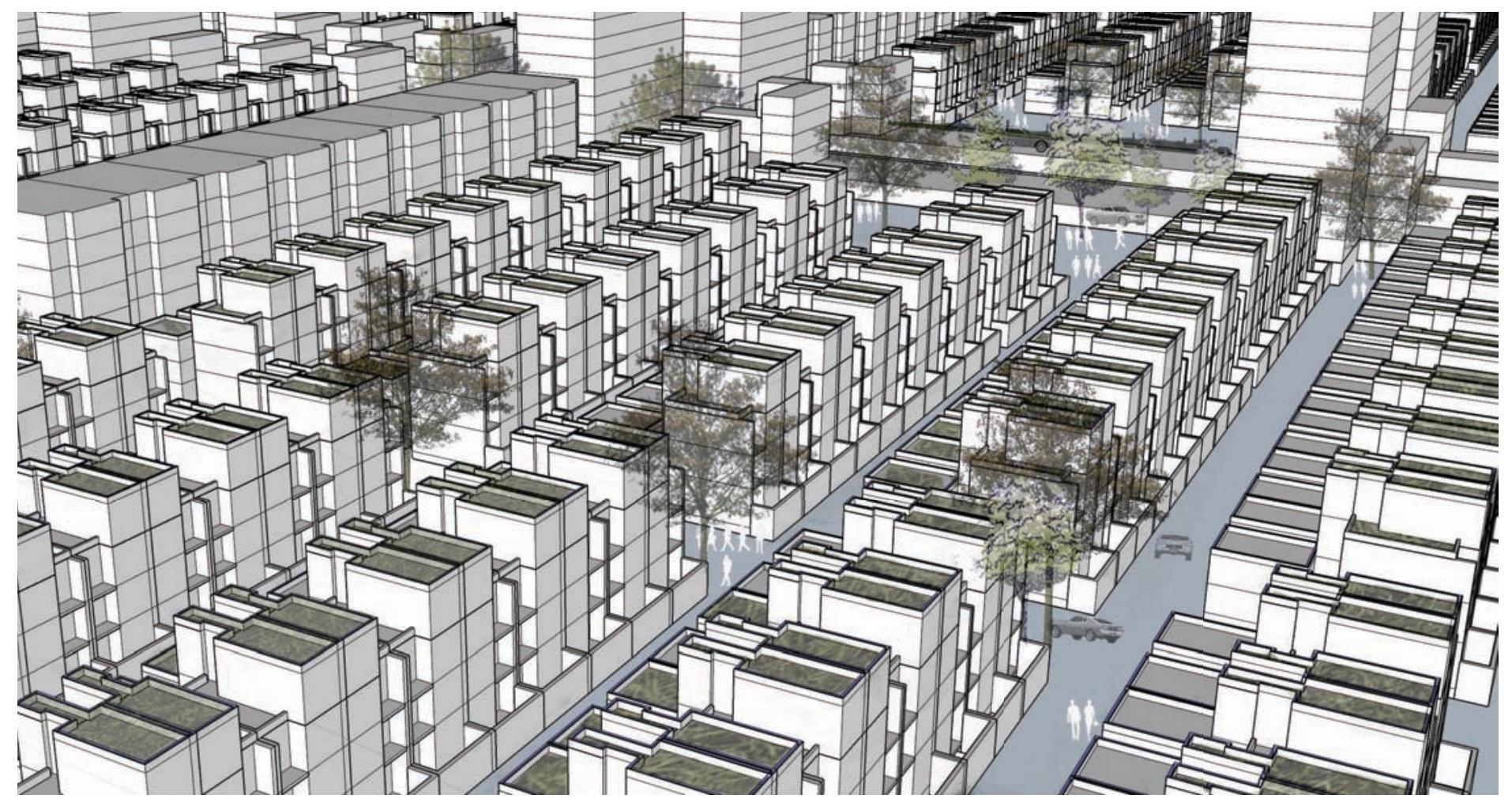



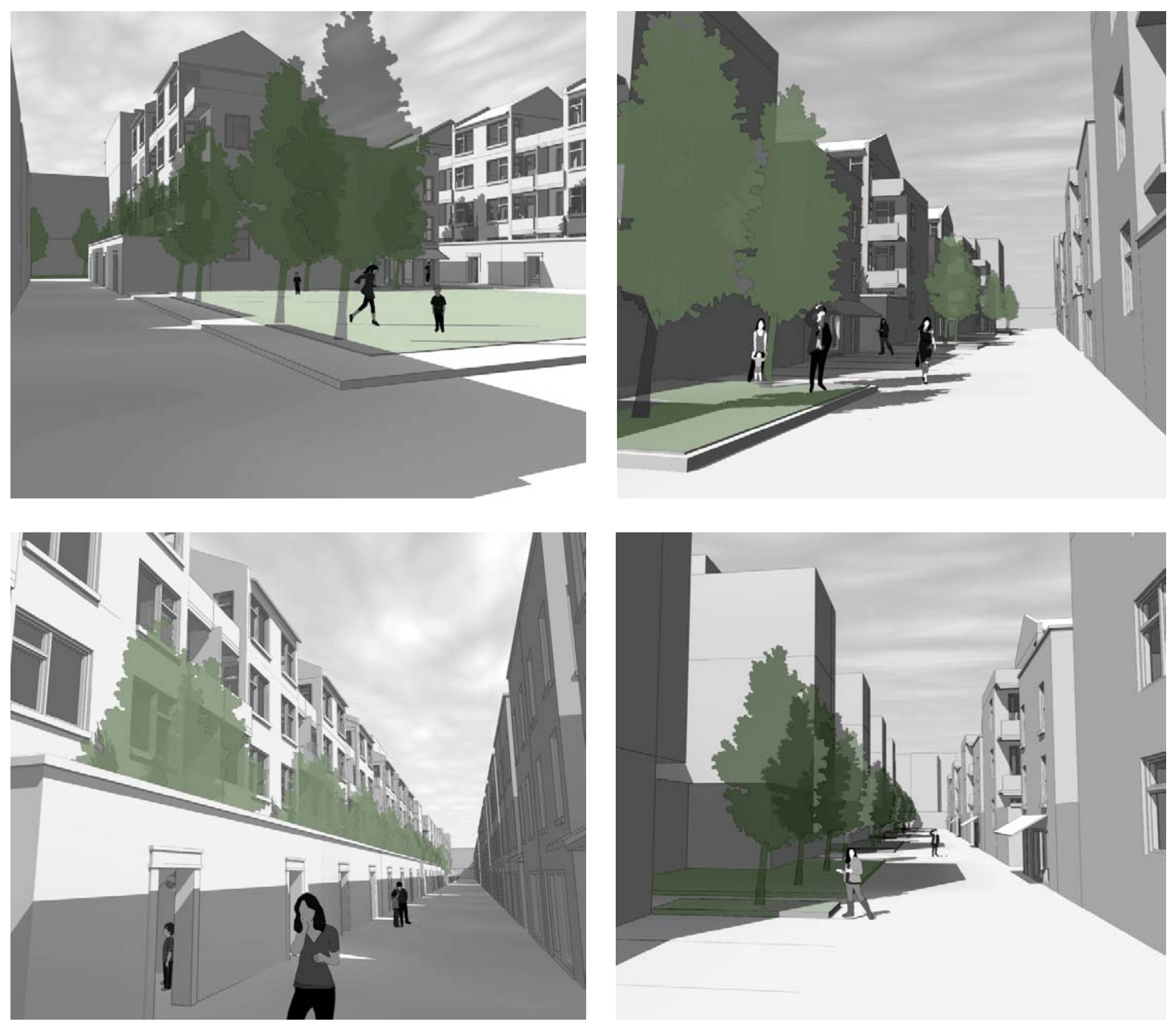

Neighborhood street 90 


\section{Part Conclusion}

The approach that China adopts to housing the "next 400 million," a large percentage of which will be rural-to-urban migrants, will have a profound effect on the ability of new arrivals to assimilate. China has opted to stay ahead of the curve with respect to the construction of housing, which consists primarily of ensembles of apartment towers. While a ready supply of housing for immigrants obviates the likelihood of informal settlements, government-issued housing towers may be too alien and rigid to aid in the transition from rural to urban life.

This thesis explores a more flexible approach to the form of mass housing, drawing on indigenous Chinese traditions. Although the current "tower in the park" approach is widely accepted and has proven successful in Hong Kong and Singapore, its long-term success depends both on its suitability for those for whom it's being built and the degree to which aggregations of tower ensembles add up to healthy and resilient urban environments.

Over the course of the research the thrust of my design explorations shifted from 
the scale of the neighborhood to that of the unit, focusing in on the redesign of the shikumen house type. Learning from the lilong, the goal was to adapt the shikumen to better work within the terms of reference of China's evolving housing market while preserving its inherent flexibility and adaptability.

While much has been written on housing for migrants, both formal and informal, my approach was to look to China's indigenous traditions for solutions that were both effective and culturally relevant. The real challenge, however, and an important next step in the research, is to verify that the proposed approach is viable within the terms of reference under which housing is currently produced in China, namely density and open-space targets, cost (to build and buy), space per inhabitant, etc. Doing so would necessitate a shift back to design explorations at the scale of the neighborhood.

Framing the project so that the design was more a part of the research would have helped to better focus the work I undertook. However, as the design response emerged over the course of the research this may not have been possible. Also, given how important the understanding of physical and social networks proved to be to the design proposal, it is an area that warrants further research. In conclusion, I believe it is important to design flexible housing not only the for migrants transition into the urban fabric, but also for the longevity and healthy social structure of a neighborhood as the urban fabric shifts and develops. As architects we can not predict the changes in economics, policies, and human identities, however we can design to accommodate change, because we know change will always happen. 


\section{Bibliography}

\section{Books}

Angel, Shlomo. Planet of Cities. Cambridge, Mass.: Lincoln Institute of Land Policy, 2012. Print.

Bracken, G. Aspects of Urbanization in China Shanghai, Hong Kong, Guangzhou. Amsterdam: Amsterdam UP, 2012. Print.

Brook, Daniel. A History of Future Cities. New York, N.Y.: W. W. Norton, 2010. Print.

Cupers, Kenny. "Designing Social Life: The Urbanism of the" Grands Ensembles"." Positions (2010):

Douglass, Mike. Globalization, the City and Civil Society in Pacific Asia: The Social Production of Civic Spaces. London: Routledge, 2008. Print.

Harvey, David. Rebel Cities: From the Right to the City to the Urban Revolution. New York: Verso, 2012. Print.

Hassenpflug, Dieter. The Urban Code of China. Basel: Birkhäuser, 2010. Print

Miller, Tom. China's Urban Billion: The Story behind the Biggest Migration in Human History. London: Zed Books ;, 2012.

Huang, Philip CC. "Chongqing Equitable Development Driven by a "Third Hand"?." Modern China 37.6 (2011)

Jie, Dong. Discourse, Identity, and China's Internal Migration: The Long March to the City. Bristol: Multilingual Matters, 2011. Print.

Liang, Samuel Y. Remaking China's Great Cities: Space and Culture in Urban 
Housing, Renewal, and Expansion. Routledge; 1 Edition, 2014. Print.

Lu Junhua, Rowe, Peter G., Zhang Jie, Modern Urban Housing in China, 18402000, Munich, London, New York; Prestel Verlag, 2001

Saunders, Doug. Arrival City: The Final Migration and Our Next World. Toronto: Knopf Canada, 2010. Print.

Shao, Qin. Shanghai Gone: Domicide and Defiance in a Chinese Megacity. New York: Rowman \& Littlefield, 2013. Print.

State of the World's Cities, 2012/2013: Prosperity of Cities. New York: Routledge for and on Behalf of UN-Habitat, 2013. Print

Urban, Florian. "8 High-Rise Shanghai." Tower and Slab: Histories of Global Mass Housing. Abingdon, Oxon [England: Routledge, 2012. Print.

Wu, Fulong. "From Work-unit Compounds to Gated Communities." Restructuring the Chinese City: Changing Society, Economy and Space. Ed. Laurence J. C. Ma. London: Routledge, 2005. Print.

\section{Websites, Film, and Articles}

Areddy, James and Davis, Bob, "China Pins Hopes on Public Housing," Wall Street Journal, Dec. 30, 2011.

Berridge, Joe, Lee Kuan Yew's Singapore - Another Way of City Building, March 23, 2015, http://www.urbanstrategies.com/blog/lee-kuan-yews-singaporeanother-way-of-city-building/. Accessed March 25, 2015.

Cupers, Kenny. "Designing Social Life: The Urbanism of the Grands Ensembles." Designing Social Life: The Urbanism of the Grands Ensembles. Web. 4 Feb. 2015. <https://www.academia.edu/1333099/Designing_Social_Life_The_ Urbanism_of_the_grands_ensembles $>$.

Garshick Kleit, Rachel. "The Role of Neighborhood Social Networks in Scatters-Site Public Housing Residents' Search for Jobs." Housing Policy Debate 12.3 (2001): 541-73. Print.

Helinä Melkas and Richard Anker, July 2003. "Migration and Socio-economic Insecurity: Patterns, Processes and Policies" Cai Fang, July 2003.

Huang, P. C. C. "Chongqing: Equitable Development Driven by a "Third Hand"?" Modern China (2011): 569-622. Print.

Huang,Y.(2004).Housing markets, governmentbehaviors, andhousingchoice:Acase study of three cities in China. Environment and Planning A, 36(1), 45-68. Retrieved from http://search.proquest.com/docview/56248743? accountid=9894

Hui, Zhou. "Housing Reconstruction in Shanghai: The Future of Vernacular 
Housing, Li-long Housing." Baufachinformation. School of Engineering, The University of Tokyo, 16 Oct. 2000. Web. 23 Jan. 2015. < http://www.irbnet.de/ daten/iconda/CIB12481.pdf $>$.

Johnson, Ian. "New China Cities: Shoddy Homes, Broken Hope." The New York Times. The New York Times, 9 Nov. 2013. Web. 9 Jan. 2015. <http:// www.nytimes.com/2013/11/10/world/asia/new-china-cities-shoddy-homesbroken-hope.html>.

Lui Gong Li: Inside a Chinese Arrival City. Http://arrivalcity.net/video/. Film.

Moise, Edwin E. "Downward social mobility in pre-revolutionary China." Modern China (1977): 3-31.

Rosenfield, Karissa. "Chinese Company Builds 57-Story Skyscraper in 19 Days" 24 Mar 2015. ArchDaily. Accessed 31 Mar 2015. < http://www.archdaily. $\mathrm{com} / \mathrm{p}=612783>$

"Shanghai - Map - National Geographic Magazine." Shanghai - Map National Geographic Magazine. Accessed January 30, 2015. http://ngm. nationalgeographic.com/2010/03/shanghai/shanghai-map.

"[Shanghai] Shang-hai and Environs 1912 University of Texas Libraries." China Historical Maps. Accessed January 30, 2015. http://www.lib.utexas.edu/maps/ historical/history_china.html

The Largest Migration in History. Http://www.economist.com/node/21548111, 2012. Film.

"The Great Transition." The Economist. March 22, 2014. Accessed February 3, 2015. http://www.economist.com/news/leaders/21599360-government-rightreform-hukou-system-it-needs-be-braver-great.

"Tsinghua Professor: Big Chinese Cities Need Slums for Migrant Workers - China Digital Times (CDT)." China Digital Times (CDT). 15 Apr. 2008. Web. 9 Jan. 2015. <http://chinadigitaltimes.net/2008/04/tsinghua-professor-big-chinesecities-need-slums-for-migrant-workers/ $>$.

"Urban Population (\% of Total)." The World Bank Data. Accessed December 27, 2014.

"Urbanization and Economic Growth." World Bank Group. Web. 11 Feb. 2015. <https://www.worldbank.org/content/dam/Worldbank/document/EAP/ China/Urban-China-SRs1-3.pdf $>$.

Wu, Weiping. "Migrant Housing in Urban China: Choices and Constraints." Urban Affairs Review 1.38: 90-119. Print.

Zhang, Ming'ai. "Rural Migrant Workers Need Housing." China.org.cn. 14 
Apr. 2008. Web. <http://www.china.org.cn/china/local/2008-04/14/ content_14949824.htm >.

"9 in 10 Families Own Their Homes." - Xinhua. Accessed February 3, 2015. http:// news.xinhuanet.com/english/china/2013-07/20/c_132558552.htm. 